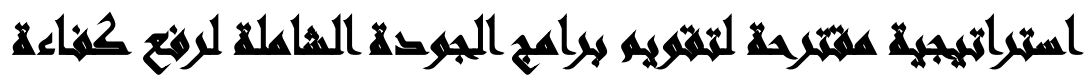

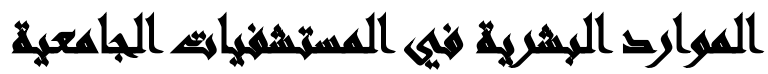

\section{[10]}

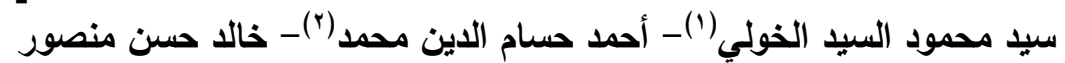

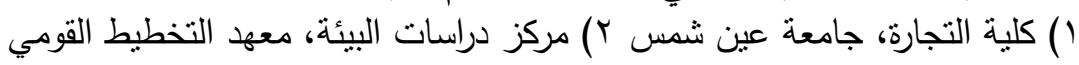

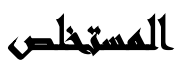

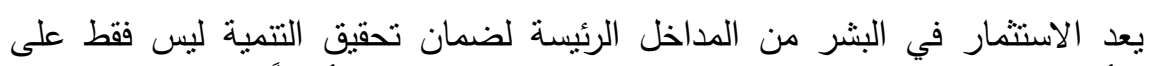

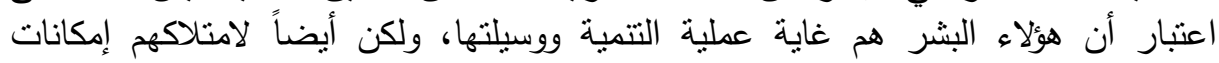

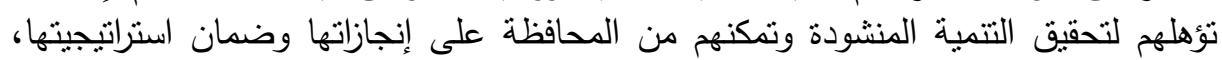

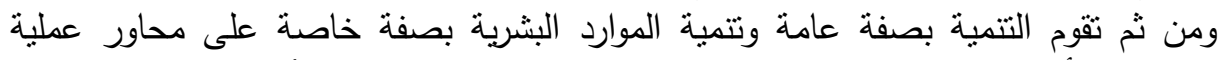

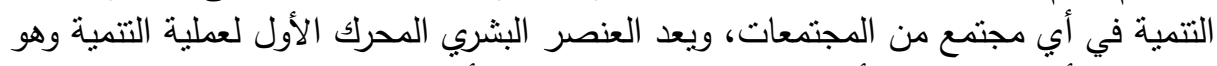

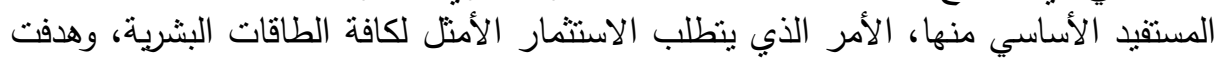

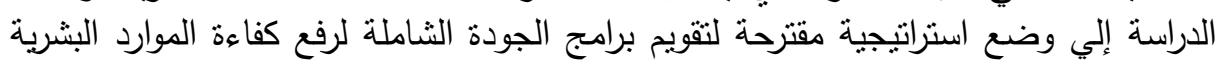

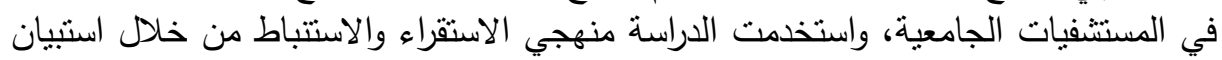

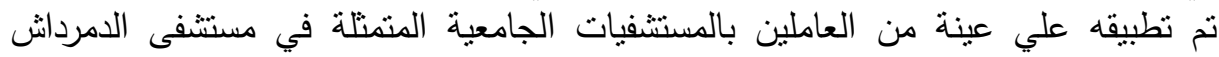

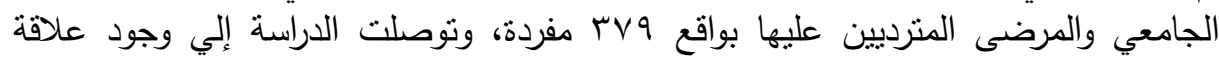

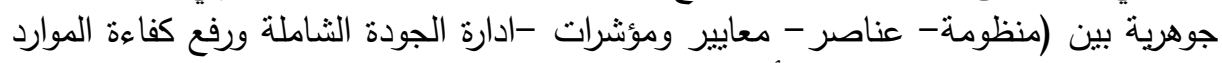

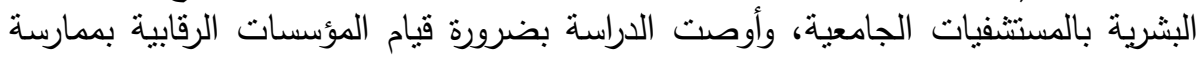

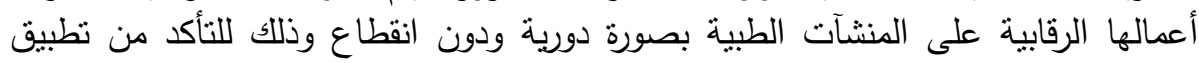
الانظمة واللوائح والقوانين الخاصة بلئ الطودة الخدمة.

\section{rasiall}

بات الاستثمار في البشر من المداخل الرئيسية لضمان تحقيق التتمية لبس فقط على

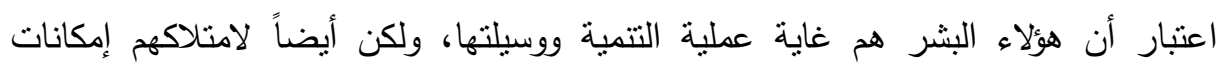
تؤهلهم لتحقيق التنمية المنشودة وتمكنهم من المحافظة على إنجازاتها وضمان استراتيجيتها، ومن ثم تقوم التتمية بصفة عامة والتتمبة البشرية بصفة خاصة على محنى محاور عملية التتمية في

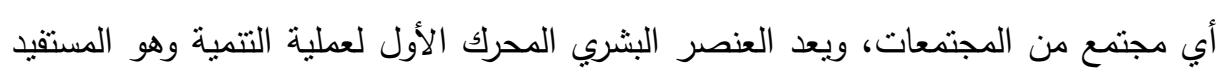

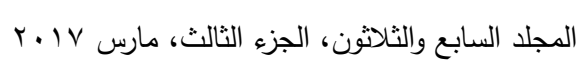


الأساسي منها، الأمر الذي يتطلب الاستثمار الأمثل لكافة الطاقات البشرية، وهناك عدد كبير

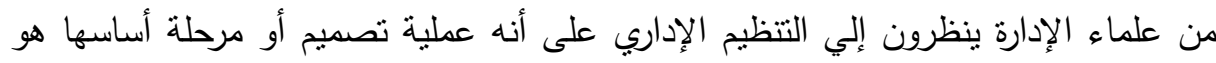

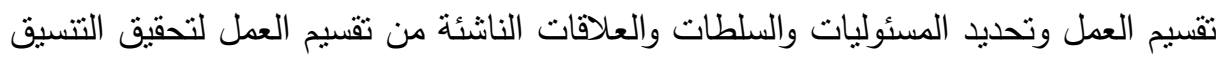
اللازم لبلوغ الهدف، ومن آراء هؤلاء العلماء يقول ليندال إن التتظيم هو تحديد أوجه النشاط ونهاط

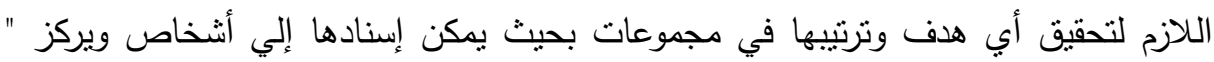
ويبر" على الهيكل التظظيمي كنشاطات مختلفة أو منمانلة وكذلك على أعضاء التتظيم القائمين بوظائفهم المنتوعة على مختلف المستويات الإدارية من تحقيق مستوى عال من الأداء وتحقيق

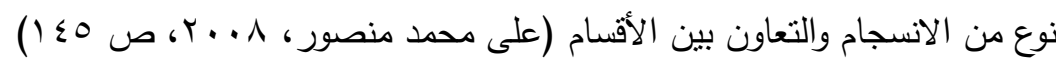

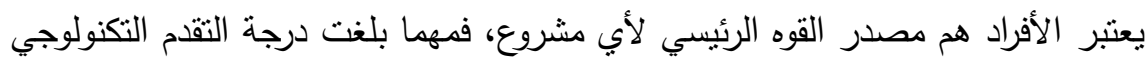

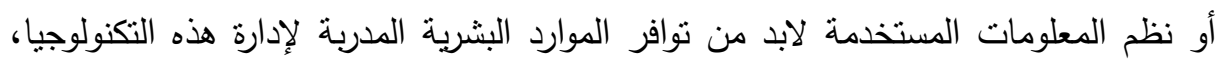

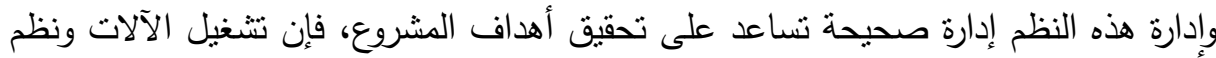

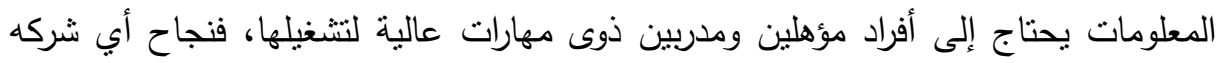
يعتمد بالدرجة الأولى على العاملين بها وعلى طرق اختيارهم وتوزيعهم على الوظائف

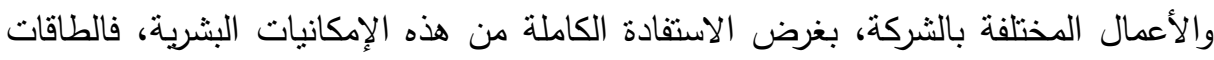

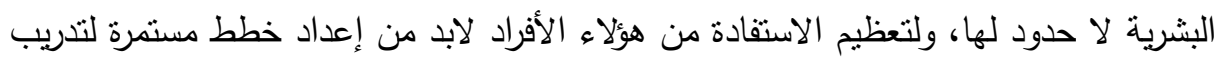
وتطوير الموارد البشرية بالمشروع، فالتدريب هو تعليم وإمداد الأفراد بالمهارات وفنون الإدادة الارة.

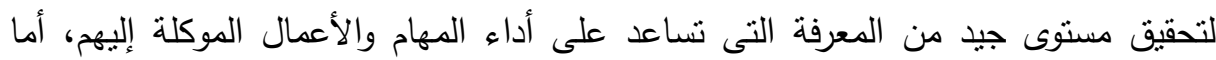
التطوير فهو التعليم المنصل بتحضير وتجهيز الأفراد لاكتساب مهارات جديدة، أو مسئوليات جديدة سواء كانت مطلوبة لعملهم الحالي أو للانتقال إلى عمل جديد، أن تعليم الأفراد مهارات جديدة بعتمد على تغيير السلوك المتبع، ويبدأ ذلك باكتساب المعرفة بنشر الوعي وادراك الأفراد لما هو مطلوب منهم ومعرفة خطوات العمل اليومية وطرق أدائها، ومع التطبيق العلمي لهي المستمر لهذه المتطلبات يتم اكتساب المهارات ويتحول السلوك الجديد إلى حالة طبيعية لتصرفات الأفراد، فأن تطوير الموارد البشرية يعتمد على اختبار الثخص الثناسب فئ المكان المناسب للعمل ويتحقق ذلك بشرح وتوصيف جميع الوظائف فى الهيكل التظظيمي، حيث يتم 
تعريف واجبات ومسئوليات كل وظيفة وتحديد المؤهلات والمهارات والخبرات المطلوبة للقيام

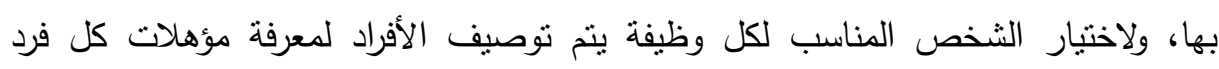

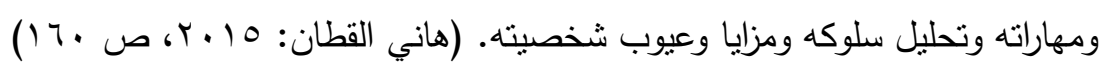

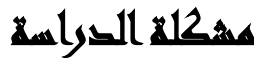

أوضحت دراسة (عصام الدين حلمى- ( . . ) ) أن هناك ضرورة لتبنى المستشفيات الحكومية لأسلوب إدارة الجودة الثشاملة بهدف تحسين مستوى الأداء الطبي والإداري

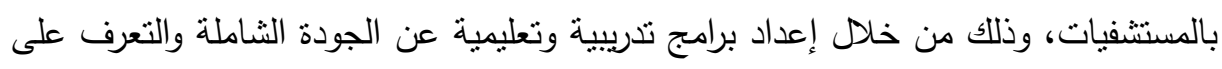

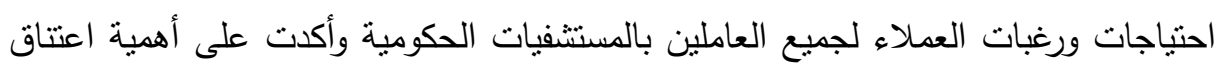

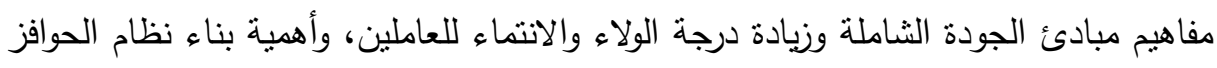

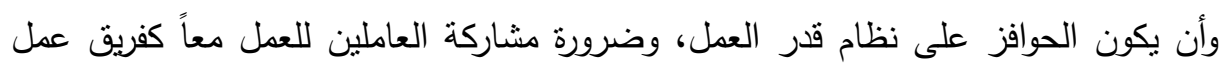

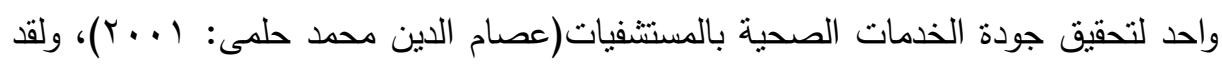

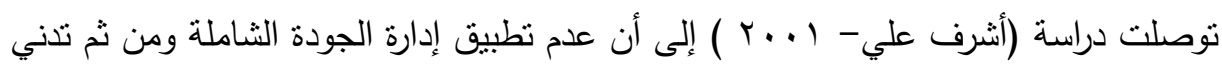
مستوى جودة الخدمة برجع إلى عدم الاهتمام الكافي بنطوير أداء العاملين بالإضافة إلى عدم إلى إنى

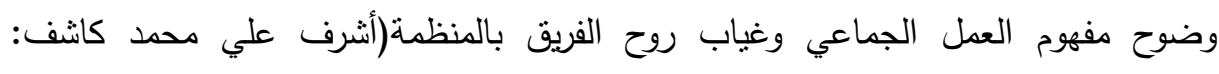

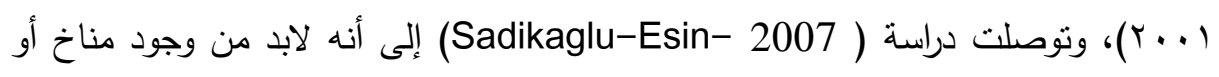

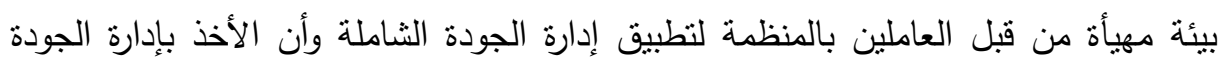

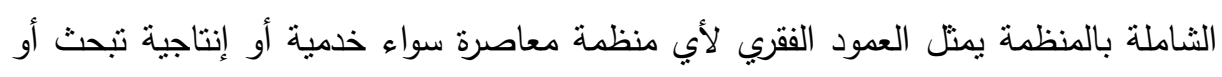

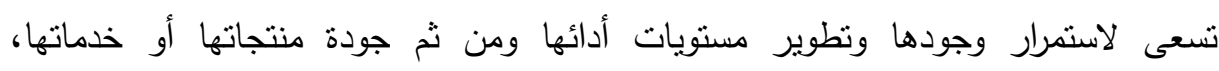
(Sadikaglu Esin:;2007) وتوصلت دراسة (Lukhwareni Matodzi- 2003) إلى أنه يوجد اهتمام كبير

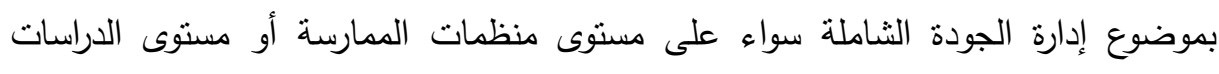
والأطر النظرية الموجودة بكليات الإدارة بأمريكا حيث إنها الأنسب من بين الأنماط التقليدية

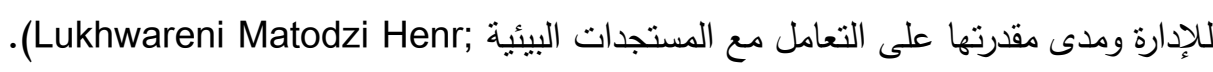


وأوضحت دراسة (عبد العزيز بن عبد اله العرب) أن المستتفيات الخاصة تطبق إدارة الجودة الثشاملة، وأن المستشفيات الخاصة تهتم بتحسين جودة الخدمات الصحية، وأوصت بن الدراسة بضرورة اهتمام المستشفيات الخاصة بوضع خطط استراتيجية وسياسية للجودة الشاملة، وضرورة الاهتمام بالتدريب المستمر والمنتظم لرفع كفاءة العاملين بها (عبد العزيز بن بن بندئ

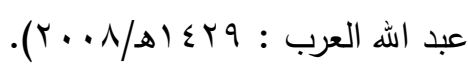
وتكمن مشكلة الدراسة بعد هذا العرض في وضع استراتيجية لتقويم برامج الجودة الثناملة لرفع كفاءة الموارد البشرية في المستشفيات الجامعية.

\section{أهمية التصراهة}

1- تتبع أهية الدراسة من كونها تتتاول كفاءة الموارد البشرية في المستشفيات باعتبارها آلية

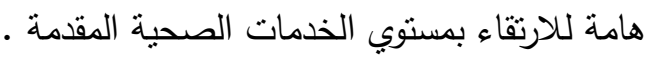
r- تتضح أيضا أهية الدراسة من جانبين الجانب الأول هو الجانب العلمي: فهي تتعلق بأهمية دراسة برامج الجودة الثاملة في المستتفيات الجامعية وصولا الي اقتراح استراتيجية النقويم تلك البرامج للعمل علي رفع كفاءة الموارد البشرية.

\section{أهماهيم الصواسلة}

1 - دراسة وتحليل الوضع الراهن لبرامج الجودة الثناملة في المستشفيات الجامعية. r- استخدام التحليل الرباعي الذي يهتم بدراسة: - رصد نقاط القوة والضعف في برامج الجودة الثاملة في المستشفيات الجامعية. - دراسة الفرص والتهديدات التي تواجه برامج الجودة الثاملة في المستثفيات الجامعية.

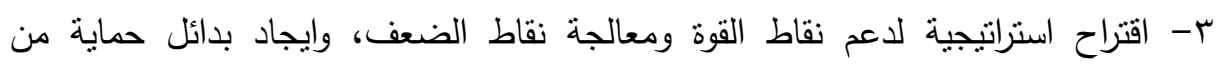
التهديدات مع تعزيز الفرص المكنة لنجاح برامج الجودة الثاملة. 


\section{هروض التواسم}

الفرض الرئيس: توجد علاقة جوهرية بين تطبيق استراتيجيات الموارد البشرية ودعم برامج

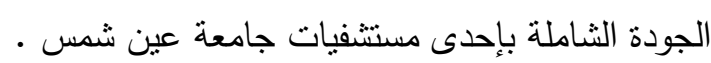

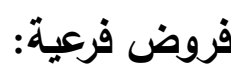
1- توجد علاقة جوهرية بين منظومة إدارة الجودة الثاملة وبين رفع كفاءة الموارد البشرية بالمسنتفيات الجامعية. r- توجد علاقة جوهرية بين عناصر إدارة الجودة الثاملة وبين رفع كفاءة الموارد البشرية بالمستشفيات الجامعية.

r- توجد علاقة جوهرية بين معايير ومؤشرات إدارة الجودة الثاملة وبين رفع كفاءة الموارد البشرية بالمستشفيات الجامعية. ع - توجد علاقة جوهرية بين تطبيق استراتيجية لتقويم برامج الجودة الثاملة وبين رفع كفاءة الموارد البشرية بالمستشفيات الجامعية.

\section{همطلحاهي التراسلة}

1- الاستراتيجية: تعرف بأنها العمل المخطط القائم على البحث والدراسة من أجل الكثف

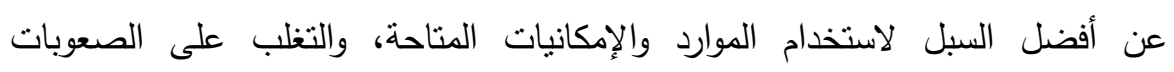

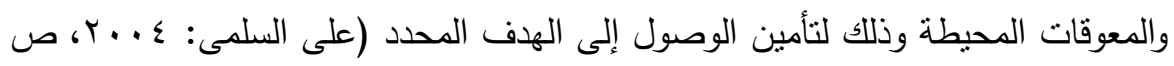

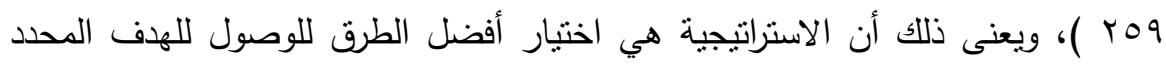

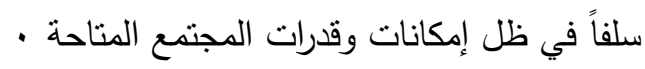
ويذهب عبد السلام أبو قحف فى مفهومه عن الاستراتيجية فى أنها برنامج عام يحتوى إنى

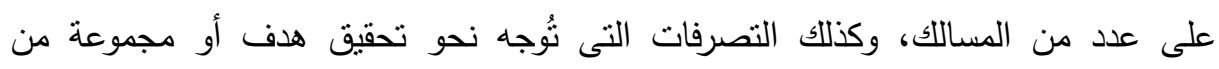

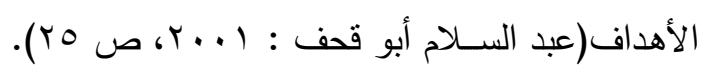


ץ - مفهوم الموارد البشرية: يمكن وصف تتمية الموارد البشرية على أنها عملية نطوير وتتمية الإنسان خلال فترة زمنيه محدده. من خلال الجوانب التالية (الصحية- الشخصية-

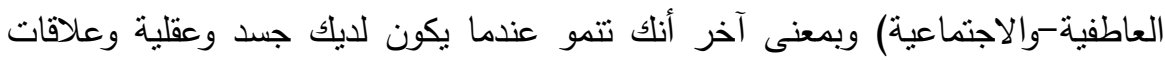

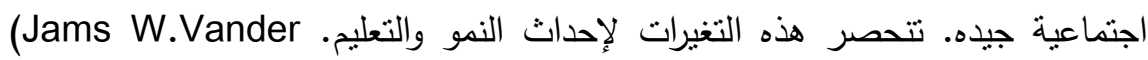
Zanden ,(2011); p3)

r- إدارة الجودة: أما إدارة الجودة : فهي المنهج النطبيقي، والأنشطة التي يبذلها مجموعة

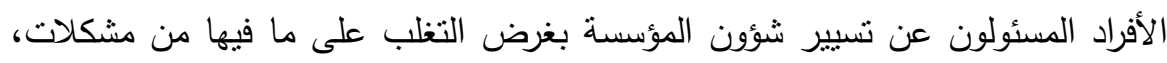
والمساهمة بشكل مباثر في تحقيق النتائج المرجوة وتحقيق حاجات وتوقعات العميل ؛ وبالتالي فهي عملية مستمرة لتحسين المنتجات والمحافظة عليها(طارق الدرادكة، مأمون

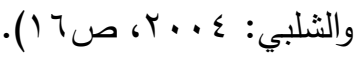

\section{التراسايس السابرية}

ا - دراسة سحر إبراهيم فلانة(ع ا • r) بعنوان قياس الأداء في المنشآت الخدمية

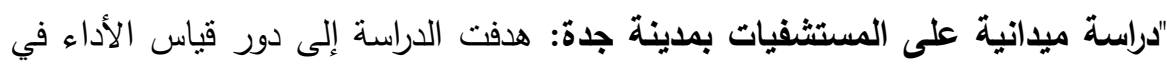

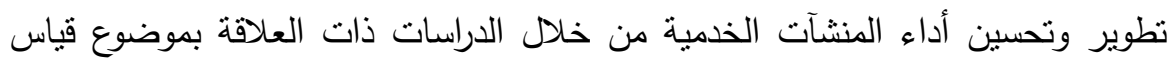
الأداء وضوابطه والمقاييس المالية وغير المالية مع أهم الانتقادات الموجهة لنظم قياس

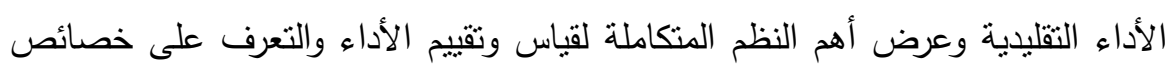
المنشآت الخدمية وأنواعها المختلفة ونظم المحاسبة الإدارية. وقد توصلت الباحثة إلى عرض النموذج المقترح المتمثل في نموذج المجددات والنتائج الذي يحتوي عليها من ستة أبعاد هي جودة الخدمة، واستغلال الموارد، والمرونة، والابتكار،

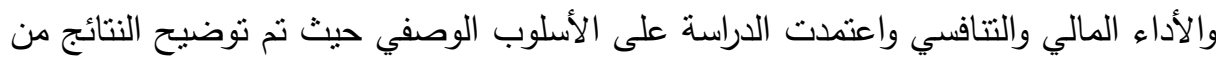
خلال البيانات المجمعة عن طريق المقابلات الثخصية وقائمة الاستقصاء. 
r - دراسة:David(11 + ب ب بنوان استخدام بطاقة الأداء المتوازن لتحقيق الأهداف الاستراتيجية بقطاع الرعاية الصحية: هدفت هذه الدراسة إلى استكثاف إمكانية استخدام

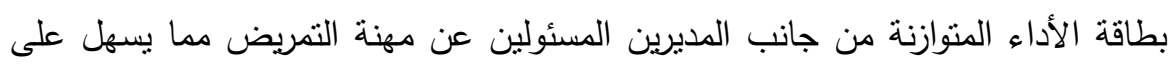

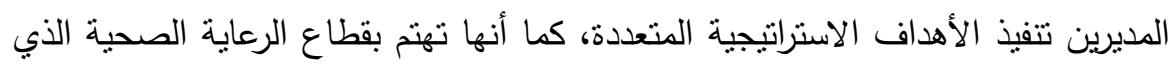
يتسم بقدر كبير من المنافسة وذلك فيما يتعلق بتوفير عاملي المرونة والجودة بالنسبة للخدمات المقدمة، بينما بتم الإقلال من التكاليف التي تتحملها المستشفى وذلك باستخدام

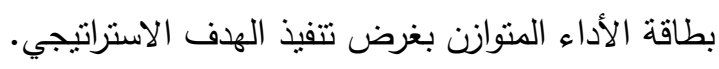

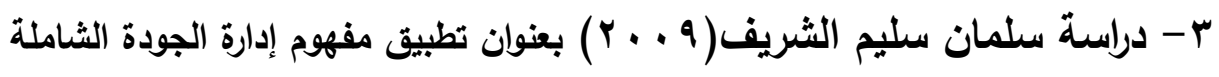
على مديريات الشئون الصحية وأثرها على تحسين أداء الرعاية الصحية بمنطقة مكة المكرمة بالمملكة العربية السعودية :استهدفت هذه الدراسة الاجابة على التساؤلات التالية: هل تتوافر المقومات الضرورية اللازمة لتطبيق نظام إدارة الجودة الثاملة بمديريات الشئون الصحية ؟،ما أهم العوائق التى تحول دون نوفر مقومات نطبيق إدارة الجودة الثاملة بمديريات الثئون الصحية ؟ ، هل يمكن التوصية بمقترحات لتأهيل مناخ العمل في لهي المؤسسات الحكومية، ومنها مديريات الثُئون الصحية كى تتتاسب مع النطبيق الفعال

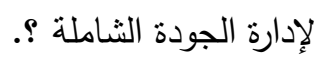

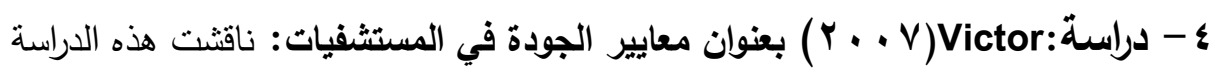
أهمية وضع معايير يمكن الاهتداء بها في مختلف المستشفيات، تتم الإنثارة إلى هذه هـانه

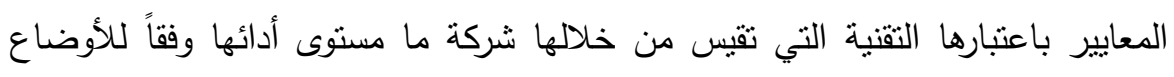
المتلى داخل الثركات النموذجية، كما أنها تحدد كيف أن هذه الثركات وصلت لهات لهذه المستويات من الأداء بالإضافة إلى أنها نستخدم المعلومات المتاحة لديها بغرض الإنهات الارتقاء بمسنوى أدائها، وتتمل المفردات التي من الممكن الاهتداء بها في في الإنتراتيجيات والممارسات التي يتم تطبيقها، وقد يقيم المرضى داخل المستشفى مستوى الجودة مقارنة

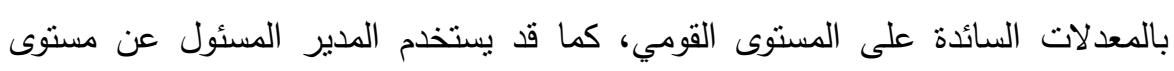

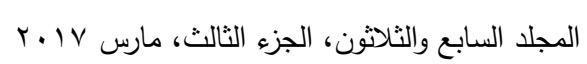


الجودة يهدف البحث إلى وضع إطار يمكن من خلاله تقويم أداء المستثفيات الحكومية مع دراسة تطبيقية على المستشفيات الحكومية، وفى ضوء تحليل النقاط الرئيسية التي أنتنمل عليها البحث ومن أهمها طبيعة الوحدات الحكومية وخصائص مخرجاتها بشكل عام والمسنتفيات بشكل خاص ونظم المعلومات فيها على اعنبار أن معرفتها والإلمام بها

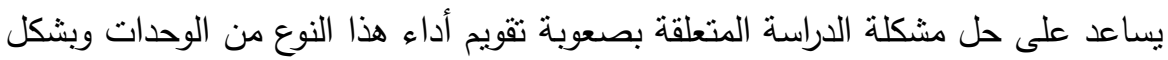
الركيزة الأساسية لتحقيق هذا البحث وقد توصل الباحث إلى أنه يمكن استخدام مؤشرات

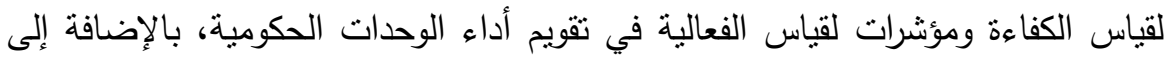
أساليب التحليل المقارن والدراسات التجريبية.

ه - دراسة نهى أحمد إبراهيم(ه . . ب ) بعنوان مساهمة الرقابة على الإدارة في تحسين جودة الخدمات المقدمة في المستثفيات المصرية العامة: هدف البحث إلى تحقيق مستوى رعاية صحية جيدة وتقديم خدمات منكاملة من خلال منهج الرقابة على الأداء

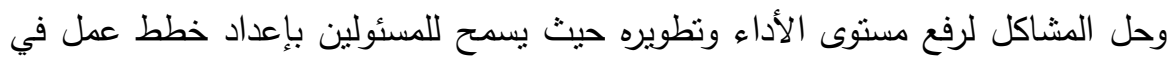

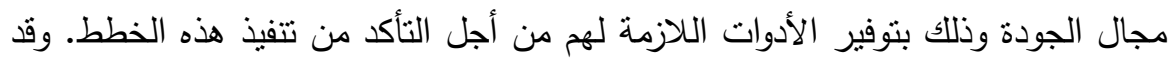
قامت الباحثة بدراسة عناصر هيكل الرقابة على الأداء المتمثل في بيئة الرقابة والنظام

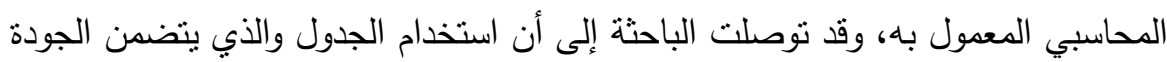

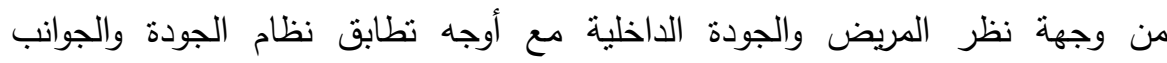
الاقتصادية على حد سواء، ومتابعة خطة تحسين الجودة عن طريق الوصول إلى معايير ومعدلات تمكن من مراقبة ومراجعة وضبط أداء فريق العمل.

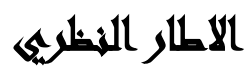

ثروة المجتمع الحقيقية تكمن أساساً في قدرات مواطنيه ومدى إدراكه وقدراتهم العلمية والتكنولوجية، الأمر الذي يدفع المجتمع إلى وضع مسألة تتمية الموارد البشرية في مقدمة

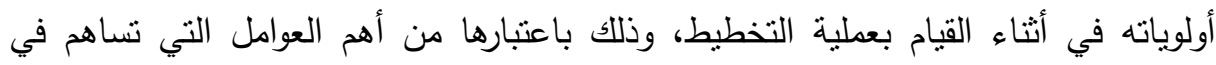

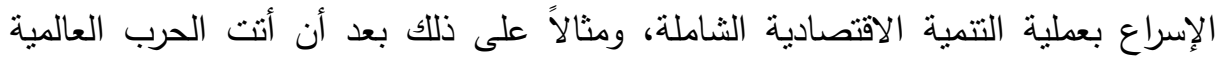

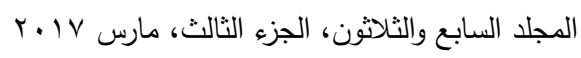


الثانية على الصرح الاقتصادي لمعظم دول أوروبا نوقع العديد من الاقتصاديين أن إعادة بناء

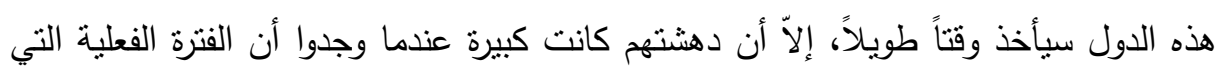

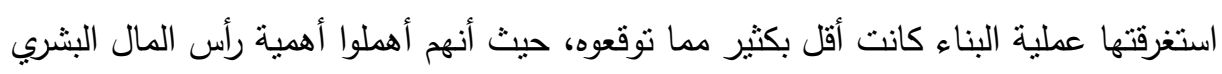
وركزوا على رأس المال المادي، إن الزيادة في رأس المال المادي لا تؤنتي ثمارها في عملية

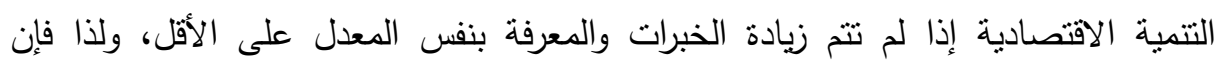

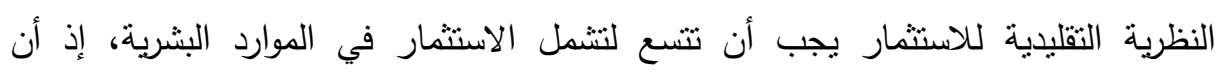
الاستثمار الأمثل سيكون استثمار العقول والكفاءات البشرية خاصة في الدول النيه النامية التئي

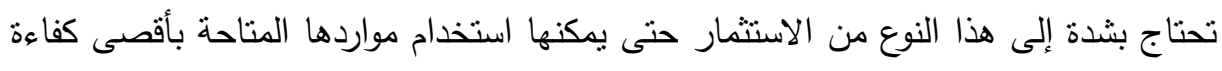

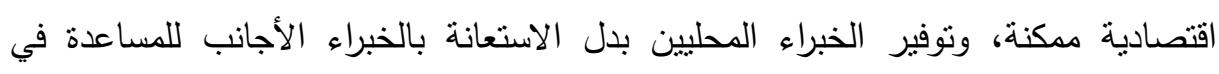
تشغيل أحدث ما وصلت إليه اختراعات الدول المتقدمة.

(Moscove, S.A., Simkin, M.G., Bagranof F, N. A. (2001) وقد تضاعف حجم الإنفاق الحكومي على تتمية الموارد البشرية في خطة التتمية التي تم

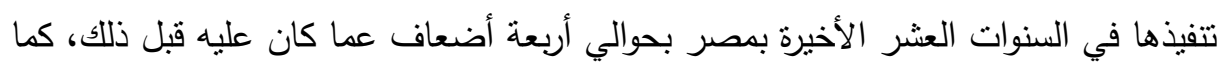

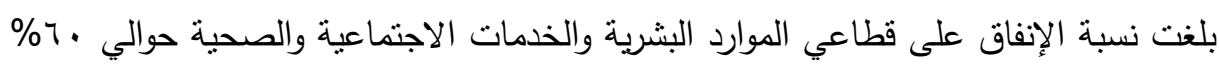
من إجمالي الإنفاق على نتمية القطاعات الأخرى. (Mundel, E.M ;2005) p.248) الأبعاد الاستراتيجية لاور إدارة الموارد البشرية:

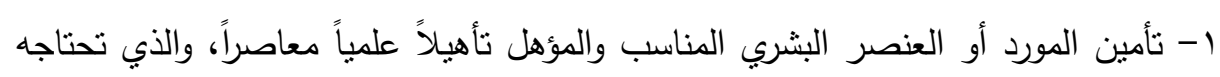
المنظمة، وذلك من خلال استراتيجية واضحة ومحددة تتكامل وتتوافق مع الاستراتيجية

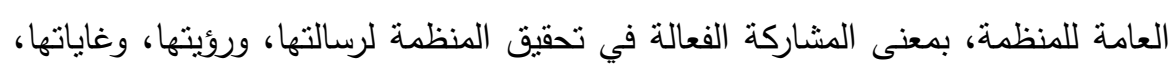

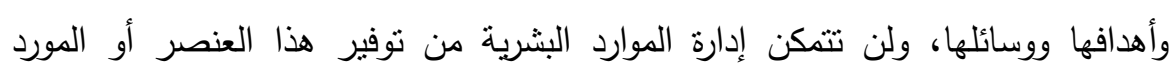

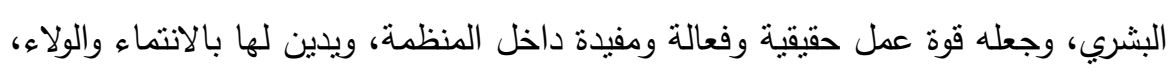

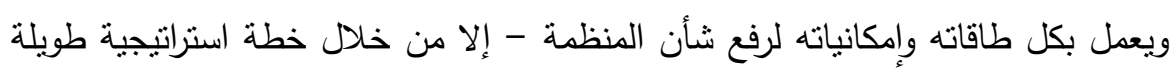

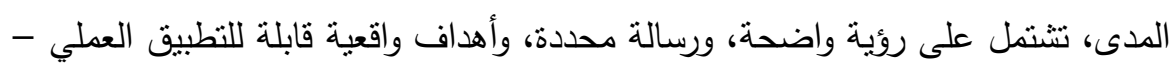
بعيدة عن الفلسفات النظرية - وسياسات وبرامج وإجراءات في مجال التحفيز المعنوي ورئي 
والمادي لهذا المورد البشري، فضلاً عن تهيئة وتوفير بيئة عمل مناسبة تمكّن هذا المورد أو العنصر البشري من استخراج إبداعاته وابتكاراته، فضلا عن القيام بأداء واجبات عمله.

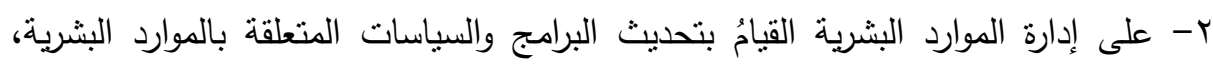

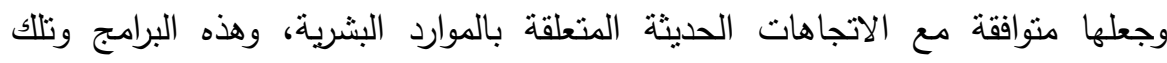

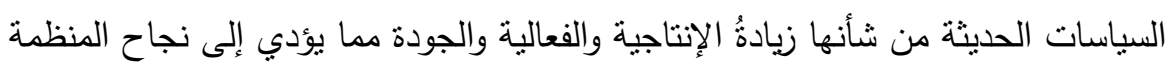

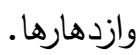
r- على إدارة الموارد البشرية أن تعمل من خلال التكامل والتتسيق والتعاون مع الإدارات الأخرى داخل المنظمة، لكي تضمن نجاح استراتيجيتها، فمسؤولية إدارة الموارد البشرية مسؤولية تشترك فيها جميع الإدارات عن طريق مديريها، وخاصة الإدارة المباشرة، والإدارة

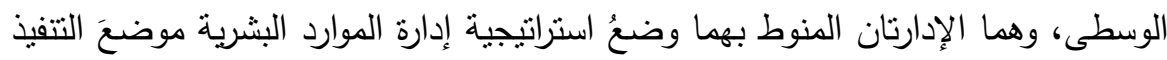

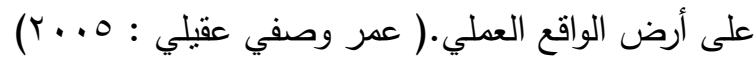
واحتلت إدارة الجودة وتطبيقاتها في الآونة الأخيرة أهمية خاصة سواء اهية على الهى الصعيد العالمي أو المحلي إذ تعتبر أحد الأنماط الإدارية السائدة والمرغوبة في الفترة الحالية وأصبحت الهت الهبه الحاجة ضرورية لتطبيقها كمدخل من مداخل التطوير التنظيمي الهادف إلى تحسين الأداء

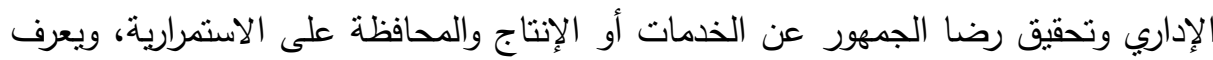

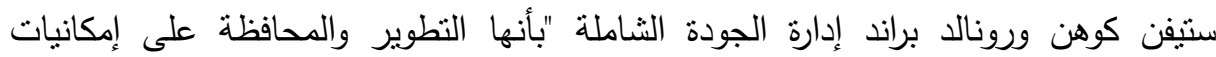
المنظمة من أجل تحسين الجودة وبثكل مستمر ، والإيفاء بمتطلبات المستفيد وتجاوزها، وكذلك البحث عن الجودة وتطبيقها في أي مظهر من مظاهر العمل بدءا من التعرف على احتياجات

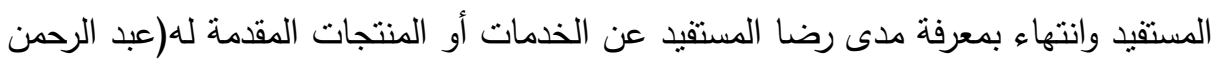

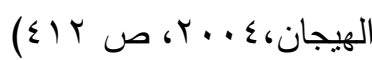

\section{الاجراءايت المنهجية الستراسة}

1 - متغيرات الاراسة: تعتمد الدراسة على متغيرين أساسيين هما: - المتغير المستقل ...... برامج الجودة الثاملة - المتغير التابع ...... كفاءة الموارد البشرية لينية 
ץ - منهجية الدراسة: اعتد الباحثون علي المنهج الوصفي التحليلي والذي تتطلب إجراء

نوعين من الدراسة:

أ- دراسة نظرية: في شكل عرض تحليلي للدراسات والبحوث السابقة المهنمة بموضوع البحث وأسلوب الدراسات المكتبية للمراجع والقراءات والدراسات العلمية العربية والأجنبية

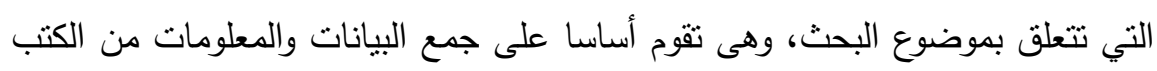
والمراجع والدوريات والمجلات العلمية المتخصصة والمرنبطة بموضوع الدوم الدراسة.

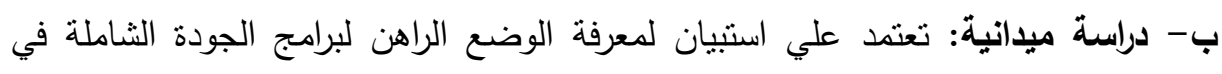

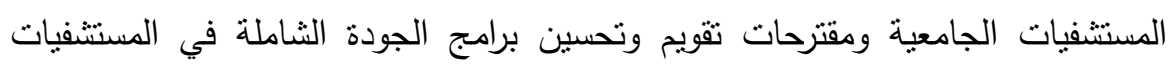
الجامعية

- الحدود المكانية ( مستشفيبي الدمرداش) . المكانية والزمنية للاراسة

- حدود بشرية ( عينة عشوائية من مختلف المستويات والقطاعات الادارية بالمستشفى ) ) .

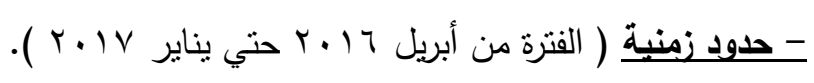
ب- أداة الدراسة

- استبيان للتحقق من فروض وأهداف الدراسة من خلا عدة محاور يحاول الباحث خلالها

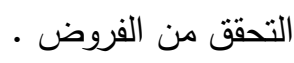

- تناول الاستبيان مجموعة من الأسئلة حول البيانات الأولية والتي تثنمل:

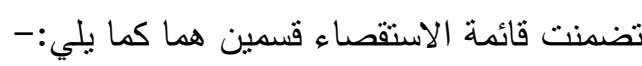
ا. القسم الأول: ويتعلق بالبيانات الديموجرافية للمبحوثين، (النوع - العمر - الوظيفة المؤهل - مدة الخبرة في الوظيفية ). r الجزع الثاني: البيانات الخاصة بمشكلة الدراسة: - مجموعة من الفقرات التي تخص العلاقة بين منظومة إدارة الجودة الثاملة ورفع كفاءة الموارد البشرية بالمستشفيات الجامعية. - مجموع من الفقرات التى تخص العلاقة بين عناصر ادارة الجودة الثاملة ورفع كفاءة الموارد البشرية بالمستشفيات الجامعية. 
- مجموعة من الفقرات التي تخص العلاقة بين معايير ومؤشرات الجودة الثاملة ورفع كفاءة الموارد البشرية - مجموعة من الفقرات التي تخص العلاقة بين تطبيق استراتيجية لتقويم برامج الجودة الثاملة ورفع كفاءة المارد البشرية

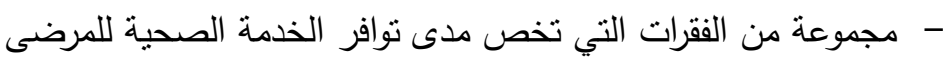
- وتتم الإجابة على فقرات الجزء الثاني وفق مقياس ليكرت التدريجي ع - مجتمع وعينة الاراسة:

مجتمع الاراسة: يتمثل مجتمع الدراسة في العاملين بالمستشفيات الجامعية المتمثلة في مستشفى الدمرداش الجامعي والمرضى المترديين عليها. عينة الاراسة: ثم اخذ عينة عشوائية من مجتمع الدراسة وتم احتساب عددها طبقاً للمعادلة الاتية: n0=Z2 حيث أن: n0

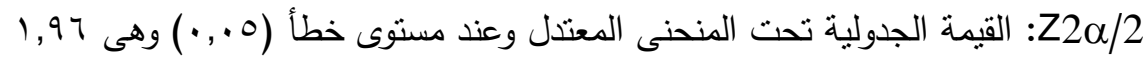
P النسبة في المجتمع (معلمة المجتمع): P

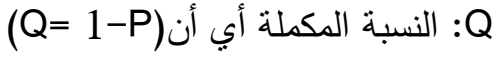

d d درجة الخطأ المسموح بها في عينة الدراسة وقد تم افتراضها من قبل الباحث (0., .•) ولقد نم احتساب نسبة عدد المفردات التي تتوافر فيها خصائص العينة محل الدراسة هي مئه

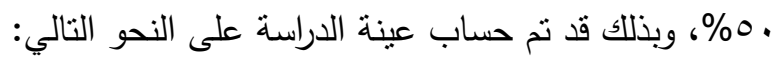
n0= (1.96) $2 \times 0.5 \times 0.5 /(0.05) 2=384$

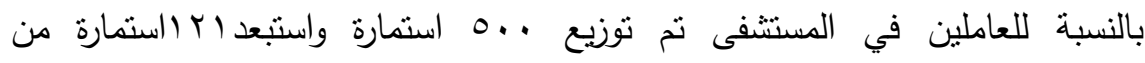

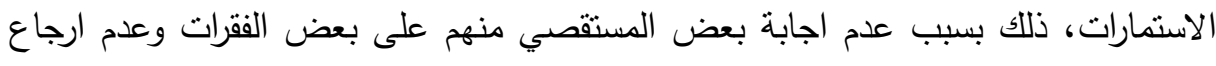

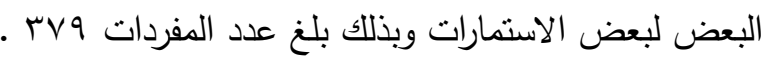


وقام الباحث بتحديد درجة الثبات والمصداقية للاراسة باستخدام معامل الفا كرونباخ،

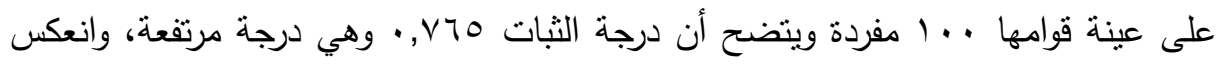

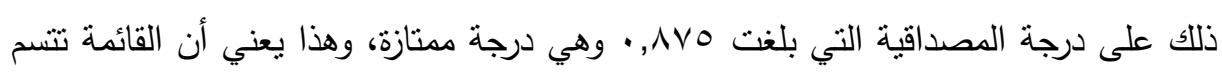

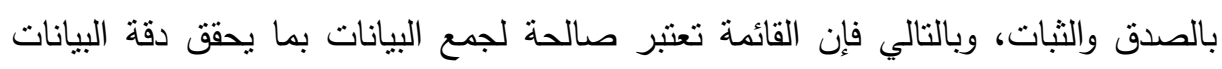
الأولية المطلوبة، والجدول التالي يوضح قيم معاملات الثبات والصدق لكل ولئ مجموعة أسئلة. جدول رقم(1 ): معامل الثبات والمصداقية

\begin{tabular}{|c|c|c|}
\hline - م الثبات & الصدامل & \\
\hline$\cdot, \mathrm{V} \mu \mathrm{\Lambda}$ & $\cdot, \wedge 09$ & 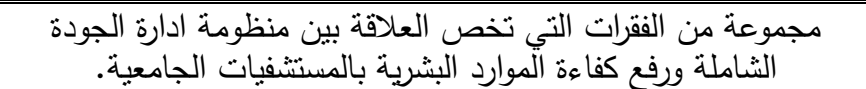 \\
\hline$\cdot, \vee \vee \leqslant$ & $\cdot, \wedge \vee \leqslant$ & 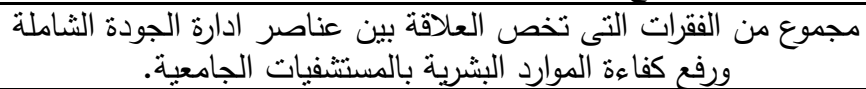 \\
\hline$\cdot, V \leq V$ & $\cdot, \wedge \uparrow \varepsilon$ & مجموعة من الفقرات التية تخص وفح العلاقةة بين معاييرة ومؤشرات الجودة البشارية \\
\hline$\cdot, \mathrm{V} 01$ & $\cdot, \wedge T \vee$ & 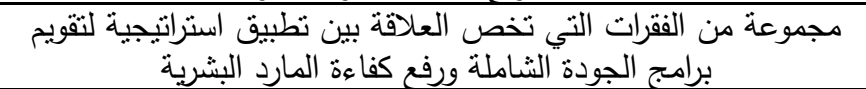 \\
\hline$\cdot, V \cdot r$ & $\cdot, \wedge \mu \wedge$ & مجموعة من الفقرات التى تخص مدى توافر الخدمة الصحية للمرضي \\
\hline$\cdot, \times 70$ & $\cdot, \wedge \vee 0$ & 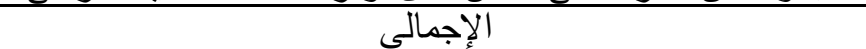 \\
\hline
\end{tabular}
جدول رقم(r): أراء عينة الدراسة في مدى توافر منظومة ادارة الجودة الثاملة لرفع كفاءة

\begin{tabular}{|c|c|c|c|c|c|}
\hline \multicolumn{6}{|c|}{ الموارد البشرية (ن= (rVq) } \\
\hline الترتيب & الاتجاه & الاختلامل & الانحراف & المتوجط & \\
\hline 10 & غير موافق & $\varepsilon \vee, \varepsilon$ & $\cdot, V Y$ & $1,0 Y$ & لا يوجد نظام لضمان الدمرداش الجودة في \\
\hline$\varepsilon$ & موافق تماما & 17,1 & $\cdot, \mathrm{V} r$ & $\varepsilon, r_{0}$ & يوجد دليل للجودة مكتوب وواضح \\
\hline 9 & 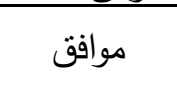 & $r, q$ & $\cdot, \wedge 9$ & 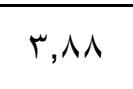 & توجديقها جميع واضعاملين للجودة الثشاملة \\
\hline r & موافق تماماً & $I V, r$ & $\cdot, \mathrm{V} \vee$ & $\varepsilon, \varepsilon \vee$ & توجد مجموعة أنشطة تهنم بجودة \\
\hline $1 \leqslant$ & غير موافق & $\varepsilon \cdot, q$ & $\cdot 77$ & 1,71 & على النطبيق والتحسين النسة تعنمر \\
\hline
\end{tabular}


تابع جدول(ץ): أراء عينة الدراسة في مدى توافر منظومة إدارة الجودة الثاملة لرفع كفاءة

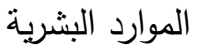

\begin{tabular}{|c|c|c|c|c|c|}
\hline الترتيب & الاتجاه & الاختلاف & المعياري & المتوسط & \\
\hline 0 & 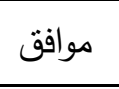 & $I V, V$ & $\cdot, \vee \leq$ & $\varepsilon, 19$ & تقوم الادارة بعلاج الاندراف النذباء \\
\hline Ir & 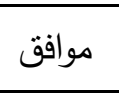 & MY,T & 1,17 & $r, 07$ & يوجد بالمستشفي نظام لدراسة \\
\hline V & 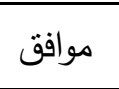 & $1 \pi, 1$ & $\cdot$, Or & $\varepsilon, .0$ & توجد معايير لمراقبة أداء ادارة \\
\hline 1 & تموافق & $1 \varepsilon, \cdot$ & • & $\varepsilon, 7 \pi$ & 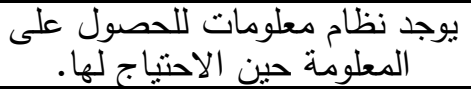 \\
\hline 7 & 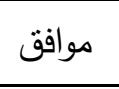 & $\uparrow \uparrow, \Lambda$ & $1, .9$ & $\varepsilon, \cdot V$ & 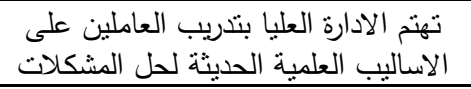 \\
\hline $1 \cdot$ & 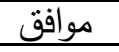 & Yo, & $\cdot, 97$ & $\Gamma, \wedge \varepsilon$ & تشجع الادارة العليا الابتكار والتطوير \\
\hline$\Lambda$ & 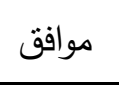 & $r^{\prime}, \Lambda$ & $\cdot, \wedge \uparrow$ & $r, q \varepsilon$ & يتم توفيب وستئل تكنولوجية العمل حديثة \\
\hline r & موافق & $1 \wedge, r$ & • & $\varepsilon, \varepsilon \mu$ & تستخدم معلومات التغذية العكسية \\
\hline 14 & 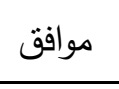 & $r \varepsilon, T$ & $\cdot, \wedge 0$ & $\Gamma, \leqslant 0$ & مجموعات فرق العاملون للانضمام الخئ بالجودة \\
\hline 11 & 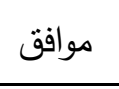 & $r q, \varepsilon$ & $1, \cdot 0$ & $r, O \mathrm{~V}$ & هناك طحاولات من أدئ العاملين بتغيير \\
\hline \multicolumn{5}{|c|}{$r \leqslant r v, \wedge$} & قيمة كاب \\
\hline \multicolumn{5}{|c|}{$\cdot, \cdot 1$} & مستوى الدلالة \\
\hline
\end{tabular}

يتضح من بيانات الجدول السابق إلى وجود اختلاف معنوي في الاهمية النسبية لآراء مفردات العينة في مدى توافر منظومة ادارة الجودة الثاملة لرفع كفاءة الموارد البشرية ذللك

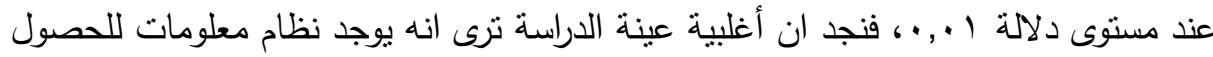
على المعلومة حين الاحتياج لها. وتوجد مجموعة أنشطة تهتم بجودة الخدمات الطبية والعلاجية ونستخدم معلومات التغذية العكسية في تحسين جودة الخدمات ويوجد دليل للجودة

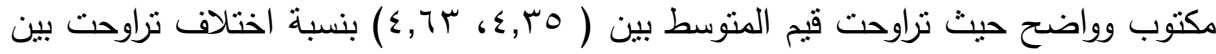

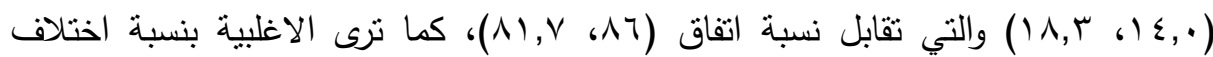




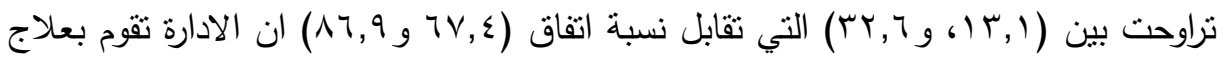
الانحراف والاسباب الجذرية للأخطاء، وان الادارة العليا تهتم بتدريب العاملين على الاساليب

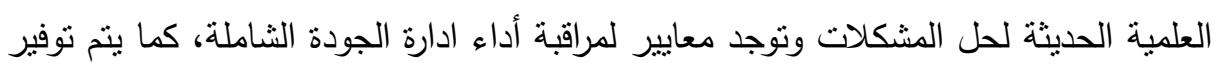
وسائل تكنولوجية حديثة وتدريب مستمر لتحسين العمل وتوجد سياسة واضحة للجودة الثاملة

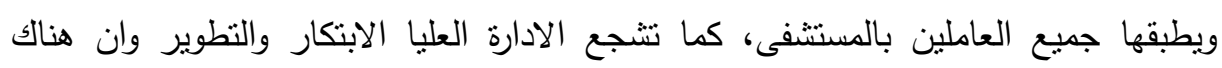

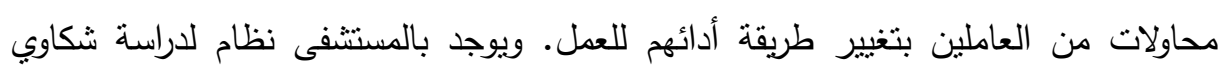

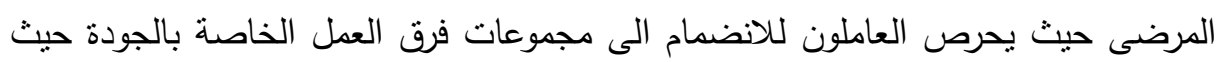
تراوحت قيم المتوسط بين (

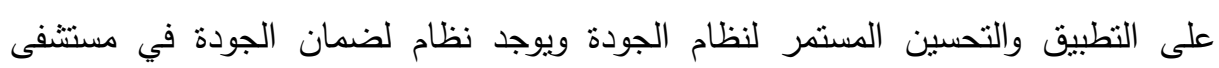
الامرداش. جدول رقم(ץ): أراء عينة الدراسة في مدى نوافر عناصر ادارة الجودة الثامل لرفع كفاءة

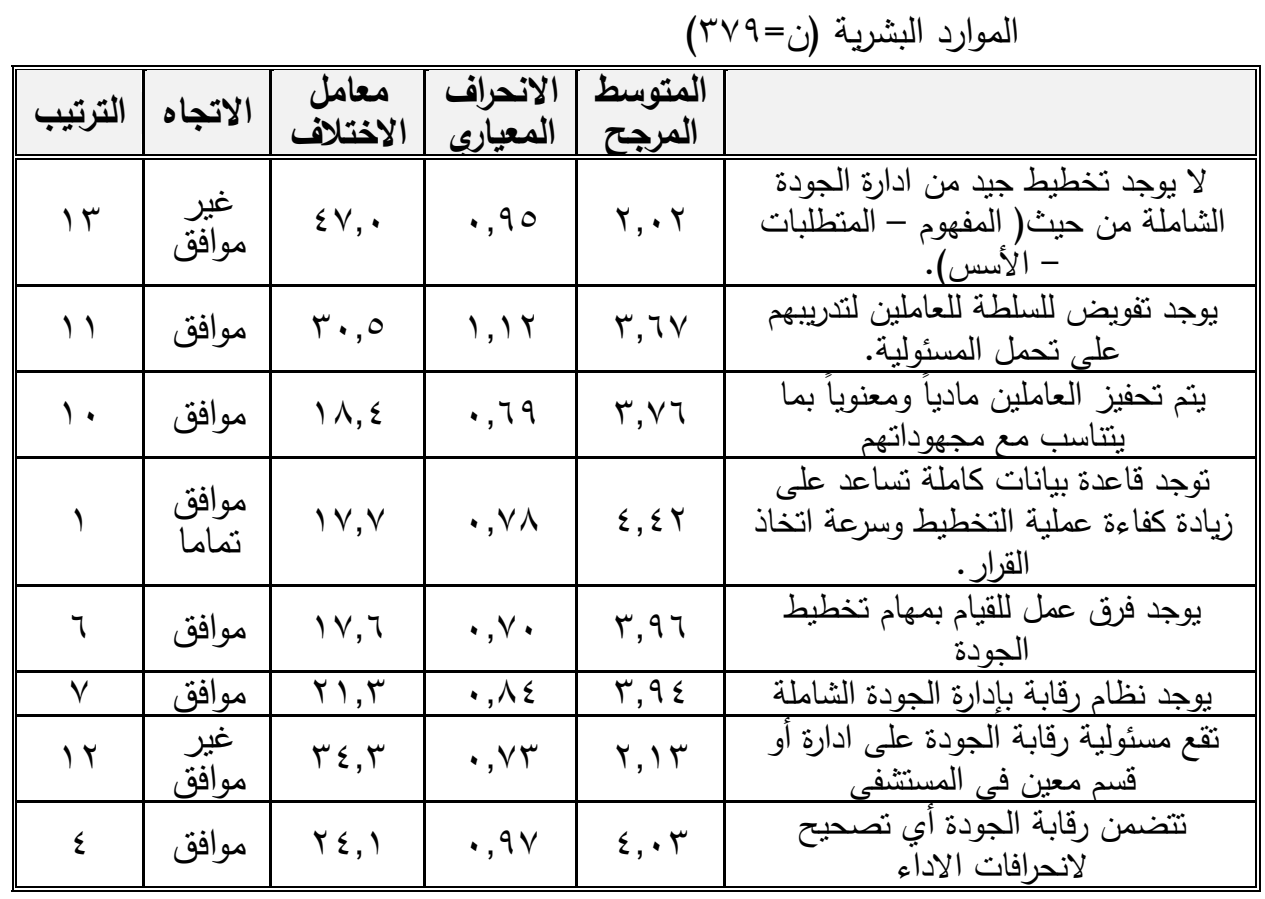


تابع جدول رقم(؟): أراء عينة الدراسة في مدى توافر عناصر ادارة الجودة الثامل لرفع كفاءة

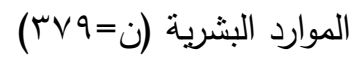

\begin{tabular}{|c|c|c|c|c|c|}
\hline الترتيب & الاتجاه & الاختلاف & المعياري & المتوسط & \\
\hline 9 & موافق & $r r, q$ & $\cdot, 9 \leq$ & $r, 94$ & تؤدي رقابة الجودة الى خفض تكلفة \\
\hline 0 & موافق & $r \varepsilon, \Lambda$ & $\cdot, 99$ & $\varepsilon, \cdots$ & يوجد نظام لتحسين الجودة للوصول الى النى \\
\hline$\wedge$ & موافق & $r_{0, q}$ & $1, \cdot r$ & $r, q \mu$ & يشمل التحسين والتطوير كل مجالات \\
\hline r & تمامافتِ & 17,1 & $\cdot, V Y$ & $\varepsilon, Y \wedge$ & 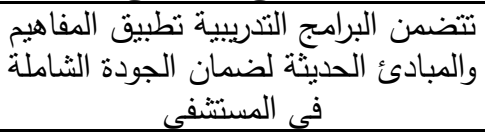 \\
\hline r & موافق & 17,0 & $\cdot, 79$ & $\varepsilon, 1 \wedge$ & تقوم الادارة بتوضيح لمعليات الأهداف والأنشطة \\
\hline \multicolumn{5}{|c|}{$1 \vee \vee 1,19$} & قيمة كاب \\
\hline \multicolumn{5}{|c|}{$\cdot, \cdot 1$} & مستوى الدلالة \\
\hline
\end{tabular}

يتضح من بيانات الجدول السابق إلى وجود اختلاف معنوي في الاهمية النسبية لآراء

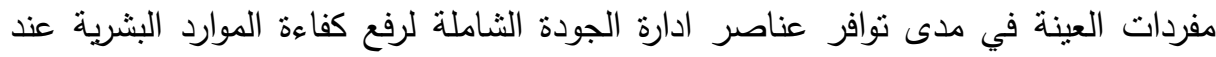

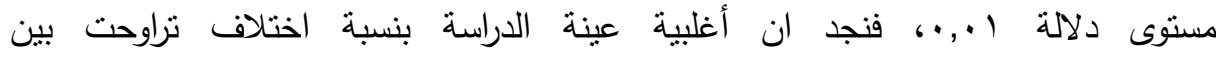

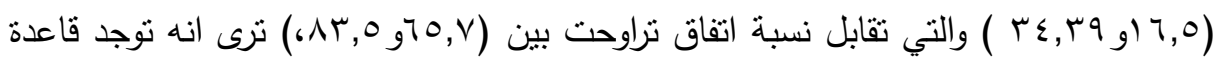

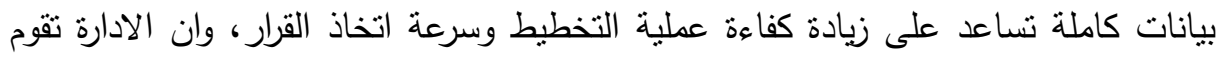

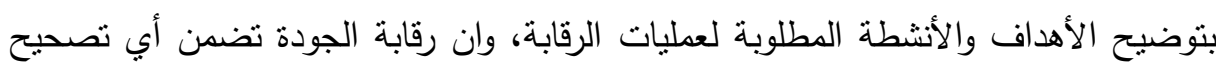
لانحرافات الاداء حيث يوجد نظام لتحسين الجودة للوصول الى افضل النتائج ونظام رقابة بإدارة الجودة الثاملة، كما يوجد فرق عمل للقيام بمهام تخطيط الجودة، حيث تؤدي رقابة الجودة الى خفض تكلفة الجودة، وان التحسين والتطوير يشمل كل مجالات العمل في المستثفى، كما يتم تحفيز العاملين مادياً ومعنوياً بما بيتاسب مع مجهوداتهم، وترى الاغلبية

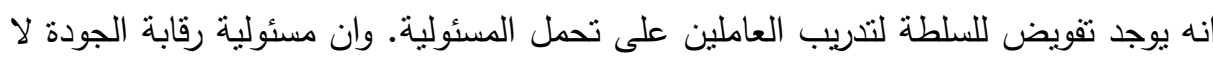
تقع على الادارة او قسم معين كما يوجد تخطيط جيد من ادارة الجودة الثاملة من

$$
\text { حيث (المفهوم - المتطلبات - الأسس). }
$$


جلول رقم(؟): أراء عينة الدراسة في مدى توافر معايير ومؤشرات الجودة الثاملة لرفع كفاءة الموارد البشرية (ن=و (rVq)

\begin{tabular}{|c|c|c|c|c|c|}
\hline القرَتِبِ & الآججاء & الإكّأة & المجبري & المشتوبط & \\
\hline $11 \mathrm{~T}$ & غُبر هوإق & $T+\mathrm{r}, \mathrm{V}$ &,$+ \leqslant 4$ & $T,+T$ & 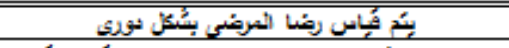 \\
\hline iT & هواثق & $+1,0$ & $\cdot, \wedge+$ & $r, \Lambda \uparrow$ & 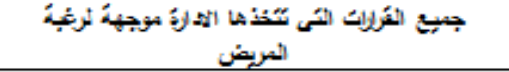 \\
\hline$\wedge$ & مواثقى & $+1,8$ & $\cdot, \wedge$ י & $€,+\uparrow$ & 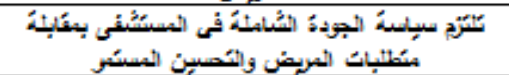 \\
\hline ir & هواثق & $\Gamma T, \Lambda$ &,$+ 4 \varphi$ & $r, \wedge v$ & 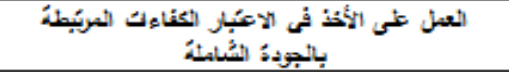 \\
\hline$\varepsilon$ & مواثقُ & iv, & $\cdot, \mathrm{V} \uparrow \cdot$ & $£, 19$ & 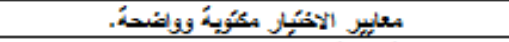 \\
\hline 19 & هواثقى & $r+4$ & Aง. & $r, v i$ & 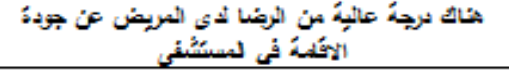 \\
\hline 1. & مواثقى & $T \leqslant, \leqslant$ & $\cdot, 9 \mathrm{~V}$ & $r, 4 \wedge$ & 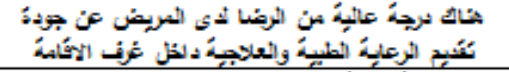 \\
\hline$\because$ & مواثق & $1 \wedge, 1$ & $\cdot, v$ & $r, 4 r$ & 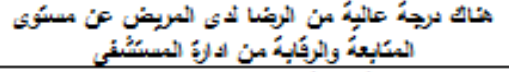 \\
\hline 4 & مواثقى & $1 \leqslant, \wedge$ &., 04 & $r, 44$ & 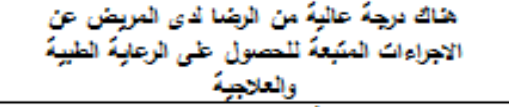 \\
\hline$\Gamma$ & مواشقي & $M, r$ & $\cdot, \mathrm{vA}$ & $\leqslant, \uparrow \wedge$ & 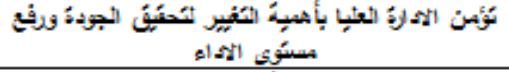 \\
\hline 10 & مواقُّ & $r \cdot, \Lambda$ &,$+ \sqrt{4}$ & $T, \sqrt{4}$ & 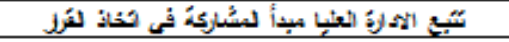 \\
\hline$v$ & مواقى & $1 \wedge, \leqslant$ & $\cdot, v \leq$ & $\varepsilon,+\varphi$ & 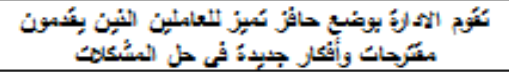 \\
\hline$r$ & مواثقي تساحًا & 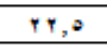 & $\cdot, 4 \wedge$ & $\varepsilon, r_{0}$ & 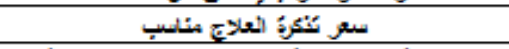 \\
\hline 1 & مواقي تُشاً & $9, r$ & , & $\xi, v T$ & 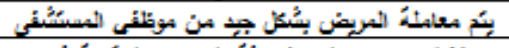 \\
\hline $1 \leqslant$ & مواقُى & $1 \wedge, r$ & $\cdot, v \cdot$ & $\Gamma, \Delta{ }^{r}$ & 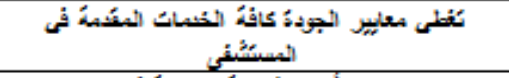 \\
\hline$\checkmark$ & هواثق & $0, v$ & $\cdot,+\pi$ & $€,+\pi$ & 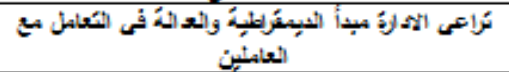 \\
\hline 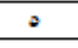 & هواثقي & $8, r$ & $\cdot,+e_{0}$ & $\leqslant,+\infty$ & 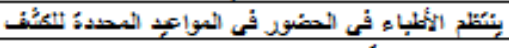 \\
\hline$r$. & غِر شواتى & $r+, 4$ & $\cdot, i r$ & 1,4, & 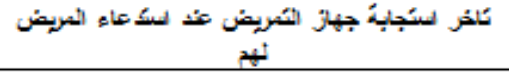 \\
\hline 11 & مواقئق & $+1,1$ & $\cdot, \Delta t$ & $r, \mathrm{Vi}$ & 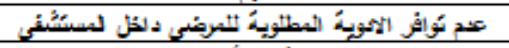 \\
\hline 19 & غِر هواتى & $\boldsymbol{r}, \wedge$ & $\cdot$, & $1,9 \mathrm{~V}$ & 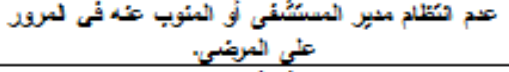 \\
\hline \multicolumn{5}{|c|}{ rerr, 1. } & 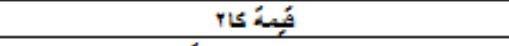 \\
\hline \multicolumn{5}{|c|}{,++1} & مستبعي الثلالةً \\
\hline
\end{tabular}

يتضح من بيانات الجدول السابق إلى وجود اختلاف معنوي في الاهمية النسبية لآراء

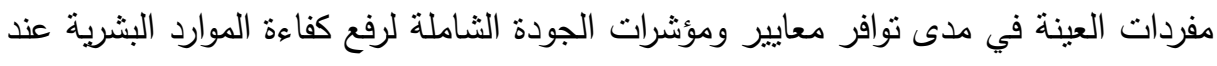

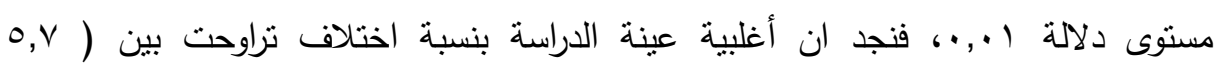

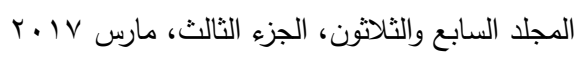




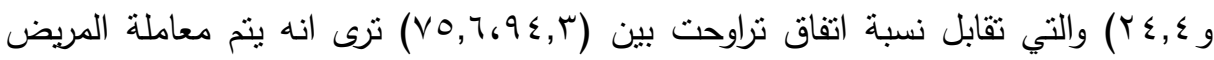

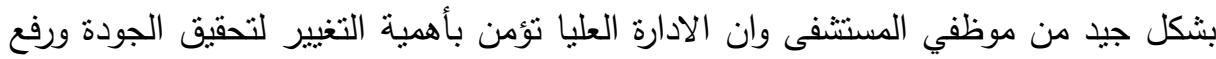

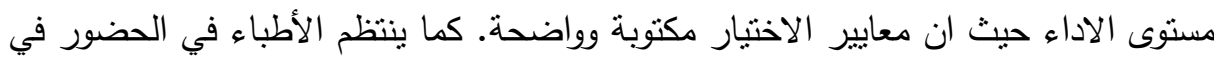

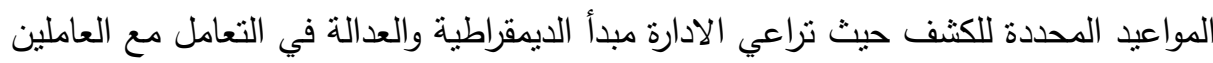
وان سياسة الجودة الثاملة تلتزم في المستشفى بمقابلة متطلبات المريض والتحسين المستمر ،

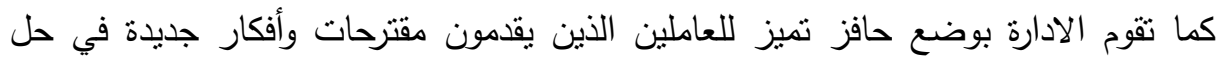
المشكلات حيث ان هناك درجة عالية من الرضا لدى المريض عن الاجراءات المتبعة

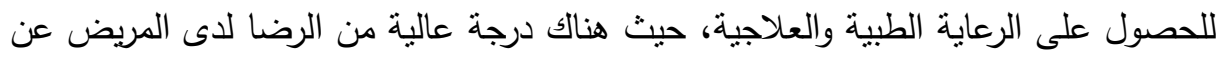

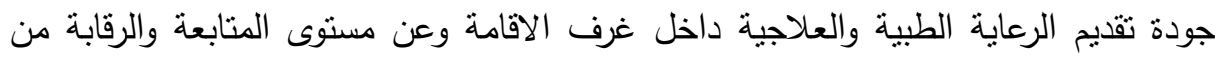

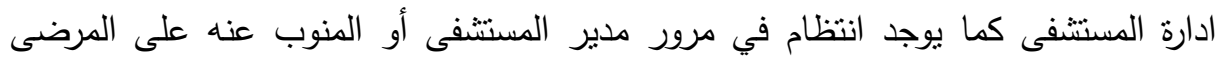
حيث لا يوجد تأخر لاستجابة جهاز التمريض عند استدعاء المريض لهم، كما تعمل الادارة

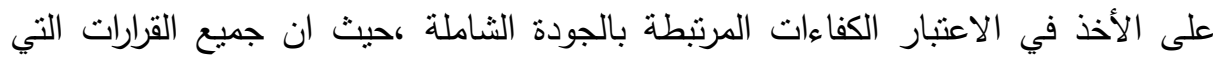

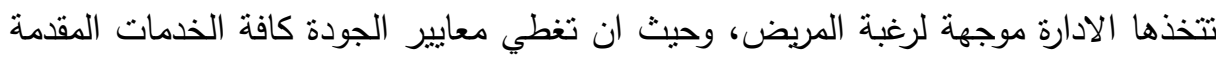

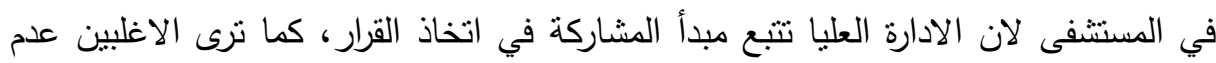
توافر الادوية المطلوبة للمرضى داخل المستتفى وانه لا يتم قياس رضا المرضى بشكل دوري.

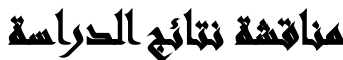

نتائج خاصة بصحة فروض الدراسة : خلصت الدراسة إلى قبول فروض الدراسة حيث أثتبت

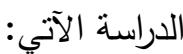
قبول الفرض الاول القائل توجد علاقة جوهرية بين منظومة ادارة الجودة الثاملة ورفع كفاءة الموارد البشرية بالمستشفيات الجامعية . قبول الفرض الثاني القائل توجد علاقة جوهرية بين عناصر ادارة الجودة الثاملة ورفع كفاءة الموارد البشرية بالمسنتفيات الجامعية 
قبول الفرض الثالث القائل نوجد علاقة جوهرية بين معايير ومؤشرات إدارة الجودة الثاملة ورفع كفاءة الموارد البشرية بالمستشفيات الجامعية قبول الفرض الرابع القائل توجد علاقة جوهرية بين تطبيق استراتيجية لتقويم برامج الجودة

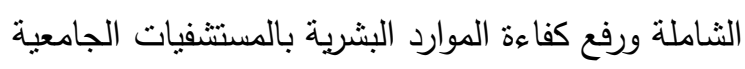

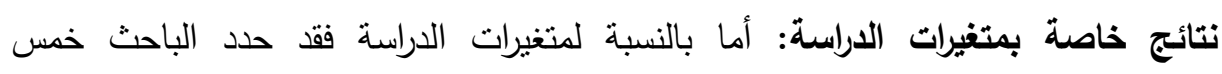

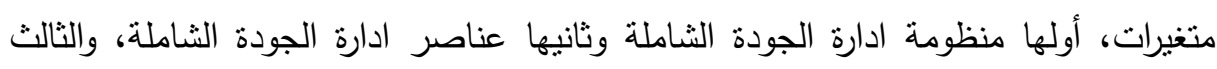
معايير ومؤشرات الجودة الثاملة، والرابع تطبيق استراتيجية لتقويم برامج الجودة الثشاملة والخامس توافر الخدمة الصحية للمرضى وكانت أهم النتائج التي توصلت إليها الدراسة الميدانية التي اجراها الباحث ما يلي:

نتائج خاصة بالفرق بين أراء عينة الدراسة طبقا للمتغيرات البات الديموجرافية:

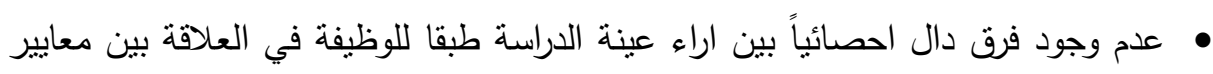

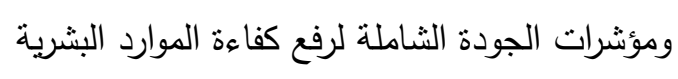

• عدم وجود فرق دال احصائياً بين اراء عينة الدراسة طبقا للوظيفة في العلاقة بين تطبيق

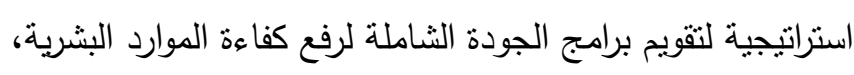

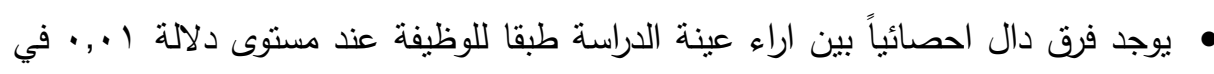
العلاقة بين منظومة ادارة الجودة الثاملة ورفع كفاءة الموارد البشرية بالمستشفيات

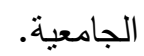

• يوجد فرق دال احصائياً بين اراء عبنة الدراسة طبقا للوظيفة عند مستوى دلالة ا..,. في

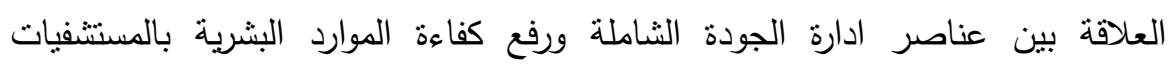

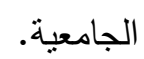

• عدم وجود فرق دال احصائياً بين اراء عينة الدراسة طبقا للمؤهل في العلاقة بين منظومة ادارة الجودة الثاملة لرفع كفاءة الموارد البشرية بالمسنتفيات الجامعية.

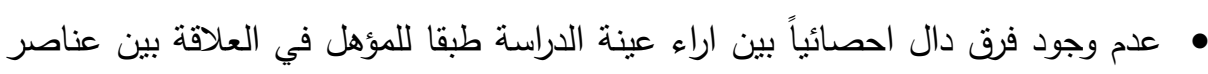

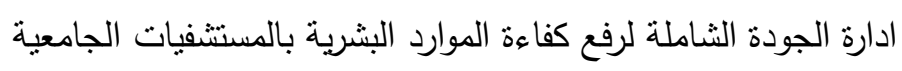


• عدم وجود فرق دال احصائياً بين اراء عينة الدراسة طبقا للمؤهل في العلاقة بين معايير

$$
\text { ومؤشرات الجودة الثاملة لرفع كفاءة الموارد البشرية. }
$$

• وجود فرق دال احصائياً بين اراء عينة الدراسة طبقا للمؤهل في العلاقة بين تطبيق استراتيجية لتقويم برامج الجودة الثاملة ورفع كفاءة الموارد البشرية عند مستوى دلاهلة

• عدم وجود فرق دال احصائياً بين اراء عينة الدراسة طبقا لسنوات الخبرة في العلاقة بين منظومة ادارة الجودة الثاملة لرفع كفاءة الموارد البشرية بالمستشفيات الجامعية.

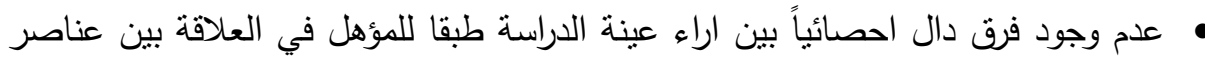

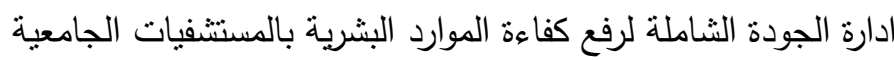

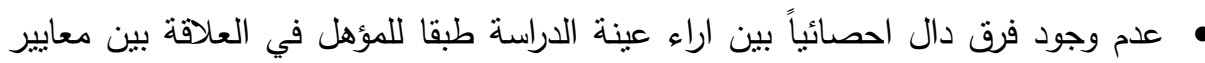
ومؤشرات الجودة الثاملة لرفع كفاءة الموارد البشرية.

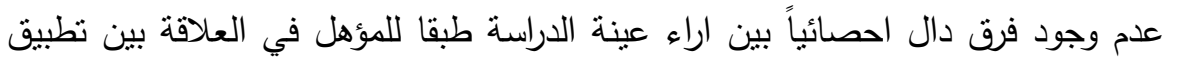

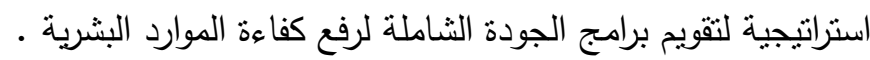

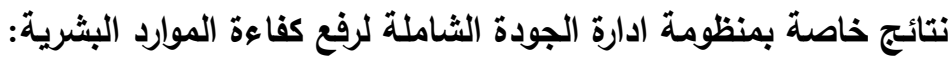
هوجد نظام معلومات للحصول على المعلومة حين الاحتياج لها. وتوجد مجموعة أنشطة تهنت بجودة الخدمات الطبية والعلاجية حيث تستخدم معلومات التغذية العكسية في تحسين جودة الخدمات ويوجد دليل للجودة مكتوب وواضح توجد معايير لمراقبة أداء ادارة الجودة الثاملة، كما يتم توفير وسائل تكنولوجية حديثة وتدريب مستمر لتحسين العمل. توجد سياسة واضحة للجودة الثاملة ويطبقها جميع العاملين بالمستشفى، كما تشجع الادارة العليا الابتكار والتطوير وان هناك محاولات من العاملين بتغيير طريقة أدائهم للعمل. هوجد بالمستشفى نظام لدراسة شكاوي المرضى كما يوجد ادارة متخصصة تعمل على فلى

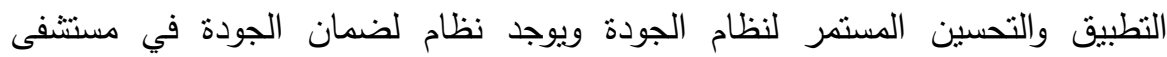
الدمرداش 
• نتائج خاصة بعناصر ادارة الجودة الثاملة لرفع كفاءة الموارد البشرية :

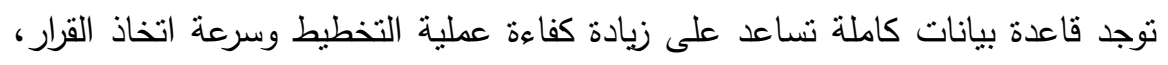

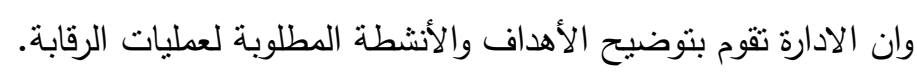

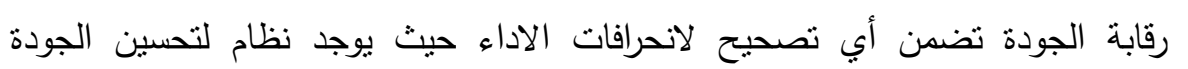

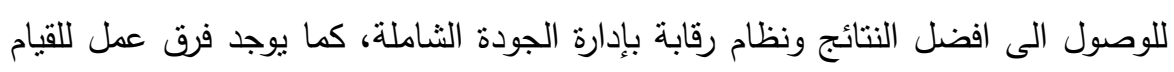

بمهام تخطبط الجودة، حيث تؤدي رقابة الجودة الى خفض تكلفة الجودة.

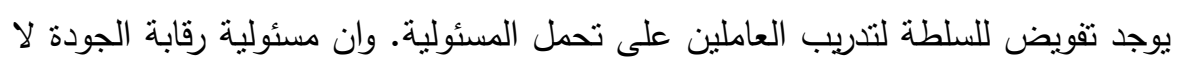

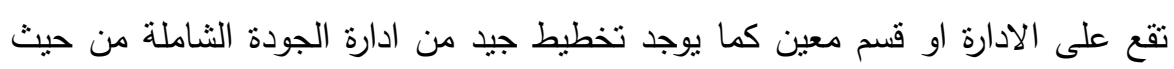

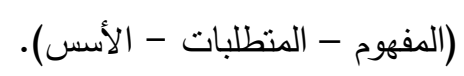

\section{نتائج خاصة بمعايير ومؤشرات الجودة الثاملة لرفع كفاعة الموارد البشرية:} • ينم معاملة المريض بشكل جيد من موظفي المستشفى وان الادارة العليا تؤمن بأهمية

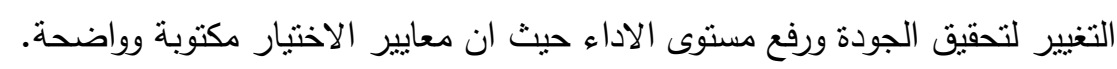

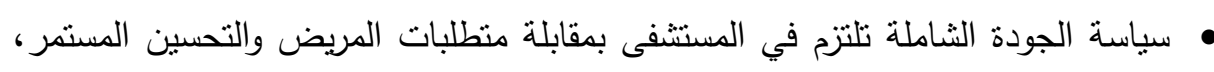

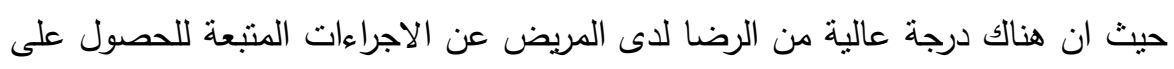

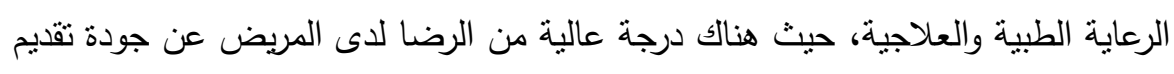
الرعاية الطبية والعلاجية داخل غرف الاقامة وعن مستوى المتابعة والرقابة من ادارة

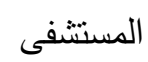
• يوجد انتظام في مرور مدير المستشفى أو المنوب عنه على المرضى حيث لا بوجد تأخر

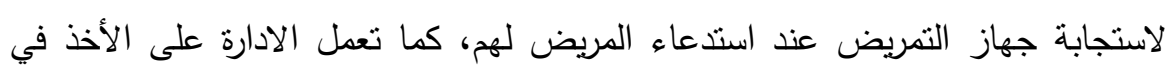

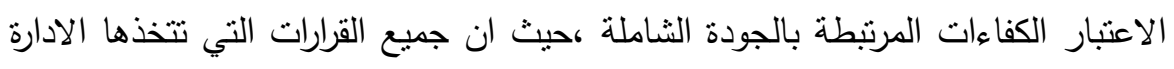
موجهة لرغبة المريض. • تغطي معايير الجودة كافة الذدمات المقدمة في المستشفى لان الادارة العليا تتبع مبدأ

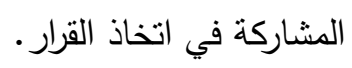




\section{نتائج خاصة بتطبيق استراتيجية لتقويم برامج الجودة الشاملة لرفع كفاءة الموارد البشرية:}

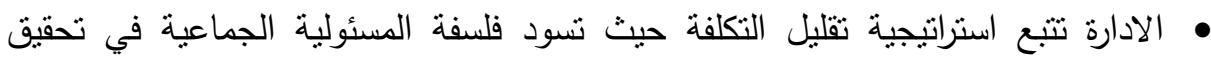
الاستراتيجية كما تؤكد الادارة على دراسة احتباجات المريض واعنبارها هدفا اساسياً لنطوير وتحسين الخدمة حيث تقوم بوضع خطة استراتيجية لادارة الجودة الثاملة. • هناك تحقيق للتكييف بين استراتيجيات المورد البشري واستراتيجية المستشفى وان الادارة العليا مدركة لأهمية نظام الجودة الثاملة ومقتتعة بنظام ادارة الجودة الثاملة.

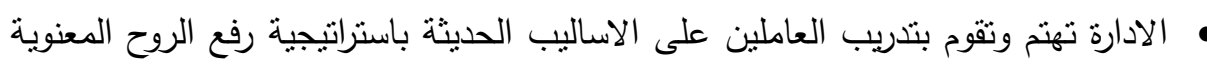

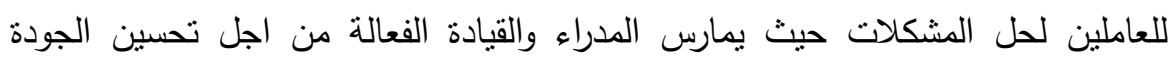
الثاملة، كما يوجد نظام متكامل لخدمة المريض كجزء اساسي من استراتيجية الجودة في المستشفى حيث يتم مواكبة النطور في تقنية المعلومات والاتصالات.

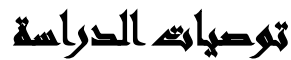

• ضرورة قيام المؤسسات الرقابية بممارسة أعمالها الرقابية على المنشآت الطبية بصورة دورية ودون انقطاع، كما يجب أن تلتزم بتحديد فترات كافية وملائمة للقيام بعمليات التفتيش على المنشآت الطبية وذللك للتأكد من نطبيق الانظمة واللوائح والقوانين الخاصة

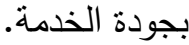
• التأكيد على التزام الإدارة العليا بالاهتمام بصفة شخصية بأنشطة رفع كفاءة الموارد

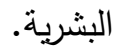
• ضرورة اهتمام المنشآت الصحية بوجود مفتش داخلي لمراقبة منظومة الجودة والتأكد من أن المنشأة تلنزم بنوفير وتطبيق جميع ما يلزم لزيادة فعالية إجراءات الجودة والارتقاء

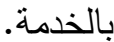
• الاهتمام بموضوع التوعية والتثقيف الجماهيري عن طريق وسائل الإعلام العامة حول أهمية الالتزام ودعم القائمين علي الجودة بالمنشآت الصحية ودورها في الحماية والحفاظ

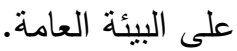




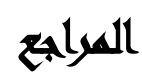

أحمد رشيد، نظريـة الإدارة العامــ(9 ـ . ب): السياسـة العامـة والإدارة، القاهرة، دار النهضـة العربية، ص الإدار العبان

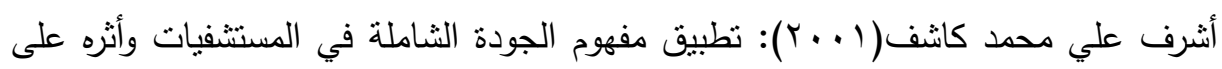

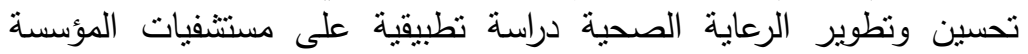
العلاجية بالقاهرة، رسالة ماجسنير غير منشورة، المعهد القومي للإدارة العليا، أكاديمية السادات للعلوم الإدارية ربالية

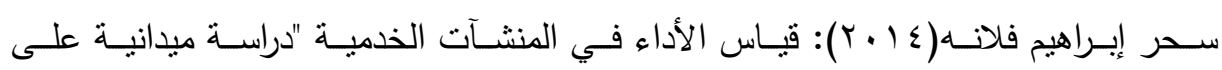
المستشفيات بمدينة جدة "، رسالة ماجستير، جامعة الملك عبد العزيز

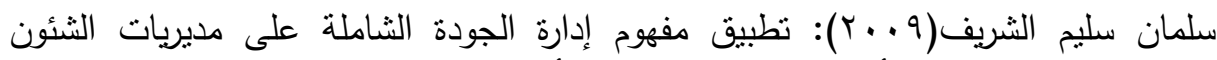

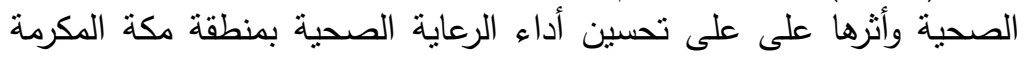

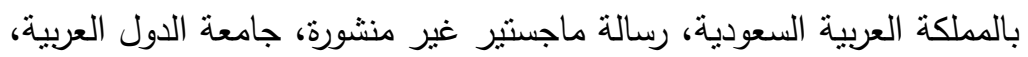

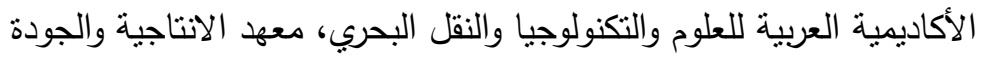

طارق الدرادكة(؟ ـ ـ ؟): مأمون والثلبي، الجودة في المنظمات الحديثة، دار صفاء، الأردن

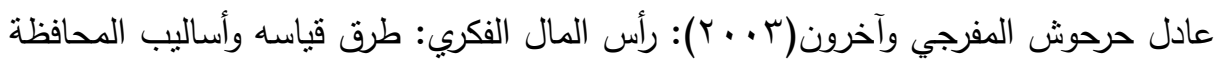

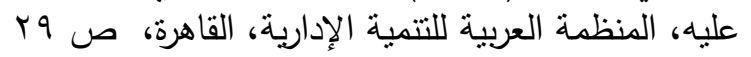

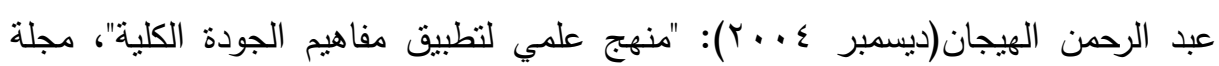

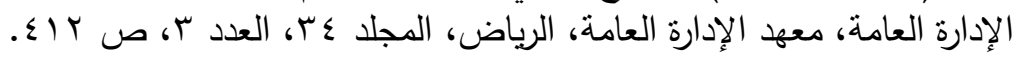

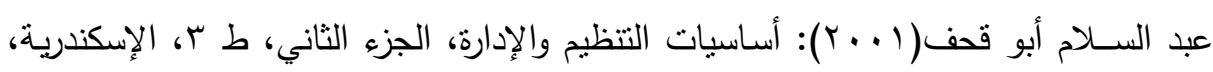

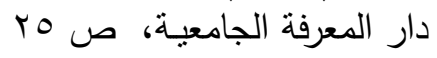

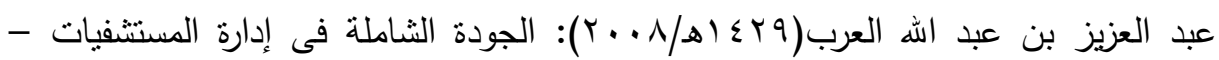

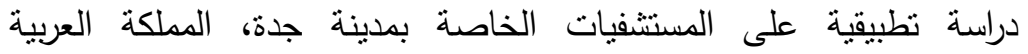

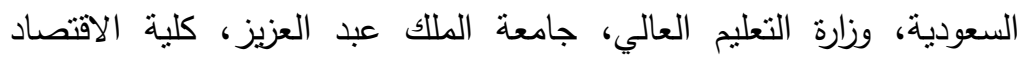
والادارة

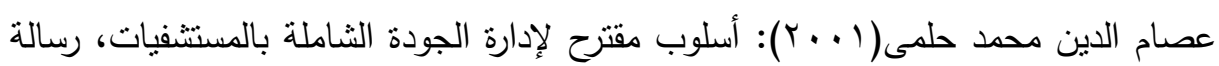

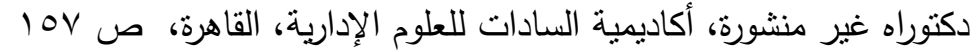

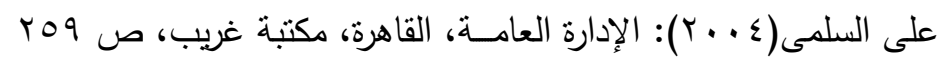

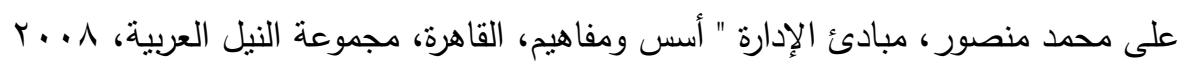

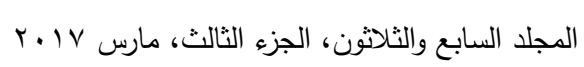


عمر وصفي عقيلي(0 × †): "إدارة الموارد البشرية المعاصرة بعد استراتيجي"، دار وائل

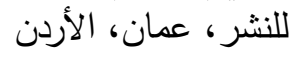

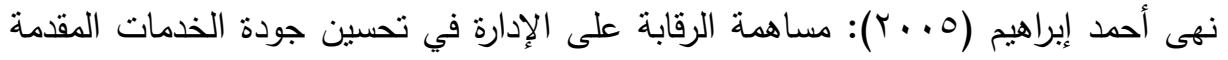

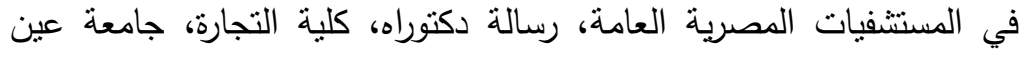

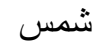

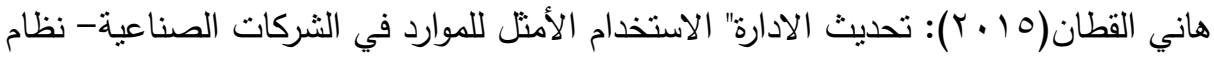

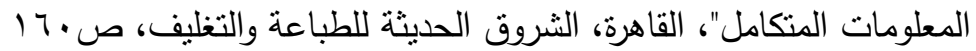

Jams W.Vander Zanden ,(2011): Human Development, seventh edition, United states of America, MC Graw -Hill Companies Inc, p3.

Lukhwareni Matodzi Henry(2003): Total Quality Management as a Response to Educational Changes in School Management, Ph.D, University of Pretoria South Africa

Moscove, S.A., Simkin, M.G., Bagranof F, N. A. (2001): Core Concepts of Accounting Informatin System, 7th ed., John Wiley \& Sons Ltd, England.

Mundel, E.M Improving productivity and Effectiveness. (N.J: PrentieeHall, Inc, Englewood Cliffs, 2005) p.248.

Naranjo - Gil,David(2011), Strategic performance in hospitals the use of balance scorecard by nurse managers ' Health Care Management Review Apr-Jun. Vol 1.341 ssue 2.p 161170.10p, 6charts

Sadikaglu Esin(2007): An analysis of the Relationship between Measurement and total quality Management, Ph.d, University of Missouri Rolla,.

Sower, Victor E(2007), "Benchmarking in Hospitals: More than a scorecard" quality progress: Aug vol, 40 Issue , p 56-60 , 3p I chart,. 


\title{
A PROPOSED STRATEGY FOR THE EVALUATION OF THE TOTAL QUALITY PROGRAMS TO ENHANCE EFFICIENCY OF HUMAN RESOURCES IN UNIVERSITY HOSPITALS
}

El-Kholy, S. M. E. ${ }^{(2)}$; Mohammed, A. H. ${ }^{(2)}$ and Mansour, Kh. H. 1) Faculty of Commerce, Ain Shams University 2) Center of Environmental Studies, Institute of National Planning

\begin{abstract}
The investment in human beings of the main entrances to ensure that the development is not only on the grounds that these people are the very development and its device operation, but also to possessing the potential that qualifies them to achieve the desired development and enables them to maintain the achievements and ensure its strategy, and then the development in general and the development of human resources in particular the axes of development in any society, is the human element first mover of the development process which is the basic of which the beneficiary, which requires the best investment of all human potential, and study aimed to develop a proposed strategy for evaluating the overall quality to raise the efficiency of human resources in university hospitals programs, and used systematic study induction and deduction through a questionnaire that has been applied to a sample of workers university hospitals of university Eldemerdash and patients hospital Almitrdaan them by 379 single, the study concludes there are significant relationship between (Mnzawmh- Anasser- criteria and indicators Manage overall quality and raising the efficiency of human resources in hospitals university, the study recommended the need for the institutions to exercise its regulatory oversight on medical facilities on a regular basis and without interruption and to ensure the application of the regulations and the laws applicable to the quality of service.
\end{abstract}

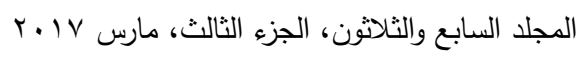

